\title{
Arcuate and Preoptic Kisspeptin Neurons Exhibit Differential Projections to Hypothalamic Nuclei and Exert Opposite Postsynaptic Effects on Hypothalamic Paraventricular and Dorsomedial Nuclei in the Female Mouse
}

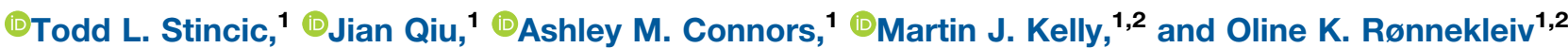

https://doi.org/10.1523/ENEURO.0093-21.2021

${ }^{1}$ Department of Chemical Physiology and Biochemistry, Oregon Health and Science University, Portland, OR 97239 and ${ }^{2}$ Division of Neuroscience, Oregon National Primate Research Center, Oregon Health and Science University, Beaverton, OR 97006

\begin{abstract}
Kisspeptin (Kiss1) neurons provide indispensable excitatory input to gonadotropin-releasing hormone $(\mathrm{GnRH})$ neurons, which is important for the coordinated release of gonadotropins, estrous cyclicity and ovulation. However, Kiss1 neurons also send projections to many other brain regions within and outside the hypothalamus. Two different populations of Kiss1 neurons, one in the arcuate nucleus (Kiss $1^{\mathrm{ARH}}$ ) and another in the anteroventral periventricular nucleus (AVPV) and periventricular nucleus ( $\mathrm{PeN}$; Kiss $1^{\mathrm{AVPV} / \mathrm{PeN}}$ ) of the hypothalamus are differentially regulated by ovarian steroids, and are believed to form direct contacts with GnRH neurons as well as other neurons. To investigate the projection fields from Kiss $1^{\mathrm{AVPV} / \mathrm{PeN}}$ and Kiss $1^{\mathrm{ARH}}$ neurons in female mice, we used anterograde projection analysis, and channelrhodopsin-assisted circuit mapping (CRACM) to explore their functional input to select target neurons within the paraventricular (PVH) and dorsomedial (DMH) hypothalamus, key preautonomic nuclei. Cre-dependent viral (AAV1-DIO-ChR2 mCherry) vectors were injected into the brain to label the two Kiss1 neuronal populations. Immunocytochemistry (ICC) for mCherry and neuropeptides combined with confocal microscopy was used to determine the projection-fields of both Kiss 1 neuronal groups. Whole-cell electrophysiology and optogenetics were used to elucidate the functional input to the $\mathrm{PVH}$ and $\mathrm{DMH}$. Our analysis revealed many common but also several clearly separate projection fields between the two different populations of Kiss1 neurons. In addition, optogenetic stimulation of Kiss1 projections to PVH prodynorphin, Vglut2 and DMH CART-expressing neurons, revealed excitatory glutamatergic input from Kiss $1^{\mathrm{ARH}}$ neurons and inhibitory GABAergic input from Kiss $1^{\mathrm{AVPV} / \mathrm{PeN}}$ neurons. Therefore, these steroid-
\end{abstract}

\section{Significance Statement}

Hypothalamic kisspeptin (Kiss1) neurons are the most gonadal steroid-sensitive neurons in the brain, and its principal neurotransmitter kisspeptin is essential for sexual development and reproduction through direct excitation of gonadotropin-releasing hormone $(\mathrm{GnRH})$ neurons. Kiss1 neurons also co-express either the classical neurotransmitters GABA, which we document is released only by Kiss $1^{\mathrm{AVPV} / \mathrm{PeN}}$ neurons or glutamate, which is released by Kiss $1^{A R H}$ neurons. Consequently, Kiss $1^{A V P V / P e N}$ neurons have direct inhibitory and $\mathrm{Kiss} 1^{\mathrm{ARH}}$ neurons direct excitatory actions onto $\mathrm{PVH}$ and $\mathrm{DMH}$ neurons known to control food intake and energy expenditure, respectively. Therefore, we have found that Kiss1 neurons have a significant input to "preautonomic" neurons known to regulate multiple homeostatic functions, which would help coordinate reproduction with these other functions that are vital for survival of the species. 
sensitive Kiss1 neuronal groups can differentially control the excitability of target neurons to coordinate autonomic functions with reproduction.

Key words: homeostasis; neural circuitry; optogenetics; preautonomic; reproduction; viral tract tracing

\section{Introduction}

Early in this century, it was discovered that that mutations in an orphan receptor GPR54 caused hypothalamic hypogonadism in humans, and deletion of GPR54 in mice resulted in defective sexual development and reproductive failure (De Roux et al., 2003; Seminara et al., 2003; d'Anglemont de Tassigny et al., 2007). It was subsequently discovered that a fragment of the peptide metastin, kisspeptin (Kiss1), was expressed in the hypothalamus and deletion of Kiss 1 also caused hypothalamic hypogonadism (d'Anglemont de Tassigny et al., 2007). Deletion of GPR54 also results in obesity in female mice (Tolson et al., 2014). The distribution and gonadal steroid regulation of hypothalamic Kiss1 neurons was quickly determined in numerous species including human for review see (Smith, 2008; Oakley et al., 2009; Lehman et al., 2013; Hrabovszky, 2014). Neurons expressing Kiss1 are located primarily in two distinct areas of the forebrain: the preoptic area (POA) and the basal hypothalamus. The preoptic Kiss1 populations in rodents are located in the anteroventral periventricular nucleus (AVPV; Kiss $1^{\text {AVPV }}$ ) and adjacent periventricular nucleus (PeN; Kiss $\left.1^{\mathrm{PeN}}\right)$, and these neurons co-express tyrosine hydroxylase $(\mathrm{TH})$, vesicular GABA transporter (vGat), and in some animal models also vesicular glutamate transporter-2 (vGlut2; Cravo et al., 2011; Zhang et al., 2013). Importantly, these rostral Kiss $1^{\mathrm{AVPV} / \mathrm{PeN}}$ neurons are positively regulated by $17 \beta$ estradiol (E2; Smith et al., 2005; Zhang et al., 2013).

The basal hypothalamic Kiss1 population is located in the arcuate nucleus of the hypothalamus $(\mathrm{ARH}$; Kiss $1^{\mathrm{ARH}}$ ) with scattered neurons also in the hypothalamic

Received March 10, 2021; accepted July 11, 2021; First published July 19, 2021.

The authors declare no competing financial interests.

Author contributions: M.J.K. and O.K.R. designed research; T.L.S., J.Q., A.M.C., and O.K.R. performed research; T.L.S., J.Q., A.M.C., and O.K.R. analyzed data; M.J.K., T.L.S. and O.K.R. wrote the paper.

This work was supported by National Institutes of Health Grants R01NS043330 (to O.K.R.) and R01-DK068098 (to O.K.R. and M.J.K.) and a grant from Oregon Health and Science University Center for Women's Health Circle of Giving (O.K.R. and M.J.K.). Confocal microscopy was supported by the NIH Grant P30 NS061800.

Ashley M. Connors's present address: Department of Biological Sciences, North Carolina State University, Raleigh, NC 27695.

Acknowledgements: We thank Martha A. Bosch for excellent technical support and assistance with creating the figures, Dan Johnson for excellent help with maintaining the mice breeding colony including doing the genotyping of mice, and Dr. Stefanie Petrie Kaech and Brian Jenkins for assistance with confocal imaging.

Correspondence should be addressed to Oline K. Rønnekleiv at ronnekle@ ohsu.edu.

https://doi.org/10.1523/ENEURO.0093-21.2021

Copyright (C) 2021 Stincic et al.

This is an open-access article distributed under the terms of the Creative Commons Attribution 4.0 International license, which permits unrestricted use, distribution and reproduction in any medium provided that the original work is properly attributed. dorsomedial nucleus (DMH; Clarkson et al., 2009; Bosch et al., 2012). The mRNA expression of the neuropeptides, including Kiss1, NKB (tac2) and prodynorphin (pDyn) within the Kiss $1^{\mathrm{ARH}}$ neurons are all inhibited by E2, whereas vGlut2 mRNA, also expressed in Kiss $1^{\mathrm{ARH}}$ neurons, and glutamate release are increased by E2 in females (Navarro et al., 2009; Qiu et al., 2018). The Kiss $1^{\mathrm{AVPV} / \mathrm{PeN}}$ neurons send direct projections onto gonadotropin-releasing hormone $(\mathrm{GnRH})$ neurons and are essential for positive feedback regulation of $\mathrm{GnRH}$ and luteinizing hormone secretion (Clarkson et al., 2008; Yip et al., 2015; Qiu et al., 2016; Piet et al., 2018). Kiss $1^{\text {ARH }}$ neurons in mice do not appear to contact $\mathrm{GnRH}$ cell bodies, but form close anatomic contacts with distal GnRH nerve processes and also exhibit neurophysiological (functional) interaction with Kiss $1^{\mathrm{AVPV} / \mathrm{PeN}}$ neurons (Yip et al., 2015; Qiu et al., 2016). Later it was discovered that Kiss $1^{\mathrm{ARH}}$ neurons project to Proopiomelanocortin and neuropeptide Y/agouti-related peptide (NPY/AgRP) neurons, which suggested that Kiss1 neurons may also be involved in regulating feeding behaviors (Qiu et al., 2018; Padilla et al., 2019). Kisspeptin immunoreactive fibers are located in many different brain regions including median preoptic nucleus (MnPO), ventral lateral septum nucleus (LSV), bed nucleus of the stria terminalis (BST), paraventricular nucleus of the hypothalamus (PVH), supraoptic nucleus (SON), lateral hypothalamus $(\mathrm{LH})$ and $\mathrm{DMH}$, suggesting widespread projections of Kiss1 neurons (Clarkson et al., 2009; Marraudino et al., 2017). However, with the exception of Kiss 1 input to GnRH neurons using the Cravo mouse model (Yip et al., 2015), the origins of these fibers are for the most part unknown. In order to study the anatomy and physiology of the two hypothalamic Kiss1 neuronal groups, various animal models expressing Kiss ${ }^{\text {Cre }}$ or Kiss ${ }^{\text {Cre:GFP }}$ have been produced (Mayer et al., 2010; Cravo et al., 2011; Gottsch et al., 2011; Yeo et al., 2016; Padilla et al., 2018). These Kiss $1^{\text {Cre }} /$ Kiss $^{\text {Cre:GFP }}$ models differ in several aspects including degree of ectopic expression and in terms of which classical neurotransmitters they express. Therefore, we used the mouse model produced by Padilla and coworkers (Padilla et al., 2018), which was found to exhibit little or no ectopic expression (see Materials and Methods). We did anterograde projection analysis, and channelrhodopsin-assisted circuit mapping (CRACM) to explore their functional input to select target neurons within PVH and $\mathrm{DMH}$, key preautonomic nuclei. These experiments revealed many common, but also several clearly separate projection fields between the two different groups of Kiss1 neurons. In addition, activation of Kiss 1 projections to PVH and $\mathrm{DMH}$ neurons, revealed excitatory glutamatergic input from Kiss $1^{A R H}$ neurons and inhibitory GABAergic input from Kiss $1^{\mathrm{AVPV} / \mathrm{PeN}}$ neurons, an indication that these neuronal group can differentially impact target neurons including those in the PVH and $\mathrm{DMH}$. 


\section{Materials and Methods}

\section{Mice}

All procedures conducted with animals were according to the National Institutes of Health Guide for the Care and Use of Laboratory Animals with approval for all of the animal use procedures from the Oregon Health and Science University (OHSU) Animal Care and Use Committee.

Kiss1 Cre:GFP version 1 (V1; Gottsch et al., 2011), but primarily Kiss $1^{\text {Cre }}$ version 2 (V2; Padilla et al., 2018), female mice were used in these experiments. In addition, Kiss $1^{\mathrm{Cre}}:: \mathrm{GnRH} \mathrm{HFP}^{\mathrm{GFP}}$ and Kiss1 ${ }^{\mathrm{Cre}}:$ :Ai32 mice were produced by crossing heterozygous Kiss $1^{\text {Cre }}$ V2 female mice with GnRH ${ }^{\mathrm{GFP}}$ mice (Suter et al., 2000) or with the reporter line Ai32 mice (Jackson, Stock No. 024109), respectively. It should be noted that Kiss $1^{\text {Cre }}$ V2 mice when crossed with a conditional reporter line, V2 mice express Kiss1 neurons in the different brain nuclei with little or no ectopic expression (Padilla et al., 2018). The animals were housed under constant temperature (21$23^{\circ} \mathrm{C}$ ) and $12 / 12 \mathrm{~h}$ light/dark cycle schedule (lights on at 6 A.M. and lights off at 6 P.M.), with free access to food (Lab Diets 5LOD) and water. Where specified, the Kiss $1^{\text {Cre }}$ V2 mice or Kiss $1^{\mathrm{Cre}}:: \mathrm{GnRH}{ }^{\mathrm{GFP}}$ mice received viral injections to express channelrhodopsin 2 (ChR2)mCherry in Kiss1 neurons (see AAV delivery below).

Kiss 1 Cre:GFP animals used in the current study have been documented to express Kiss1, NKB, pDyn, and Slc17a6 (Vglut2) mRNAs in Kiss1 ${ }^{\mathrm{ARH}}$ neurons and has been found to release kisspeptin, NKB and glutamate on activation (Gottsch et al., 2011; Qiu et al., 2018). Importantly, this animal model does not express S/c32a1 ( $v G A T)$ or release GABA from Kiss $1^{\mathrm{ARH}}$ neurons (Nestor et al., 2016; Qiu et al., 2016, 2018). The Kiss $1^{\text {AVPV/PeN }}$ neurons in the same animal model have been documented to express Kiss1, TH, and S/c32a1 (Vgat) mRNAs and found to release kisspeptin and GABA when activated, but do not express (S/c17a6) Vglut2 mRNA or release glutamate (Zhang et al., 2013, 2015; Qiu et al., 2016). Given that Kiss $1^{\text {AVPV/PeN }}$ neurons in other Kiss $1^{\text {Cre animals have }}$ been found to co-express S/c32a1 and also S/c17a6 mRNAs (Cravo et al., 2011), we have included studies to further document the diverse expression of Vgat and Vglut2 in the two populations of hypothalamic Kiss1 neurons in the animal models used in the current study (Gottsch et al., 2011; Padilla et al., 2018).

\section{AAV delivery}

Only Kiss $1^{\text {Cre }}$ (V2) animals were used for Cre-dependent ChR2-mCherry injections. Fourteen to $21 \mathrm{~d}$ before each experiment, Kiss $1^{\text {Cre }}$, and Kiss $1^{\text {Cre }}:: G n R H^{G F P}$ male or female mice ( $>60 \mathrm{~d}$ old) received bilateral AVPV/PeN or $\mathrm{ARH}$ injections of a Cre-dependent adeno-associated viral (AAV; serotype 1) vector encoding ChR2 fused to mCherry fluorescent protein (AAV-EF1 $\alpha$-DIO-ChR2:mCh). Using aseptic techniques, anesthetized mice $(1.5 \%$ isoflurane $/ \mathrm{O}_{2}$ ) were placed in a Kopf stereotaxic apparatus and received a medial skin incision to expose the surface of the skull. Once bregma was identified, the Kopf stereotaxic alignment tool (Model 1905) was used to level the head $(y:-1.200)$. Next, the bregma to $\lambda$ distance was measured and compared with the expected size of 4.21 $\mathrm{mm}$. The final $y$-coordinates were adjusted to account for deviations from this average length. For $\mathrm{ARH}$ injections, two holes were drilled into the skull at designated coordinates from bregma ( $x$ : $\pm 0.33 \mathrm{~mm}$; $\mathrm{y}:-1.185 \mathrm{~mm})$. In order to deliver the virus, a glass micropipette (Drummond Scientific \#3-000-203-G/X) was fabricated with a Narishige PE-2 puller and beveled (tip diameter $=45 \mu \mathrm{m}$ ), back filled with mineral oil and front loaded with an aliquot of AAV using a Nanoject II (Drummond Scientific). The pipette tip was positioned at $x$ : $-0.33 \mathrm{~mm}$ lateral; $y:-1.185$ $\mathrm{mm}$ and lowered to $\mathrm{z}=-5.800 \mathrm{~mm}$ (surface of brain $\mathrm{z}=0.0 \mathrm{~mm}$ ). Of note, the Kiss $1^{\mathrm{Cre}}$ (V2) $x \mathrm{GnRH}$ mice typically had a larger bregma to $\lambda$ distance and standard $y$ coordinates were often scaled up 5-15\%. Next, the AAV $\left(2.0 \times 10^{12}\right.$ particles $\left./ \mathrm{ml}\right)$ was injected at a rate of $100 \mathrm{nl} /$ min (300 $\mathrm{nl}$ total), raised to $-5.70 \mathrm{~mm}$ for a second injection (200 $\mathrm{nl}$ total) and then left in place for $10 \mathrm{~min}$ postinjection. Then, the pipette was slowly removed from the brain, pausing briefly at $-5.5,-5.0$, and finally $-4.5 \mathrm{~mm}$. The pipette was then fully retracted and moved to the other hemisphere, now $x=+0.33 \mathrm{~mm}$, and the process was repeated. The skin incision was closed using VetaBond (3 M) skin adhesive, and each mouse received analgesia (carprofen; $5 \mathrm{mg} / \mathrm{kg}$, sc). For AVPV/PeN injections the same leveling and measurement steps were taken, and the coordinates were $x: \pm 0.33, y: 0.55, z$ : -5.1 and -4.7 . To better cover the longer and thinner shape of the AVPV/PeN, the virus was injected at two sites separated by $0.5 \mathrm{~mm}(300 \mathrm{nl} / \mathrm{site}, 100 \mathrm{nl} / \mathrm{min})$. Unlike the $\mathrm{ARH}$, the pipette was left in place for $10 \mathrm{~min}$ after injection at each site to allow for even distribution of the virus and to limit viral reflux as the pipette was withdrawn from the brain.

\section{Ovariectomy (OVX) and estradiol treatment}

When necessary, at least $7 \mathrm{~d}$ before each experiment, ovaries were removed while under isoflurane inhalation anesthesia (Piramal Enterprises Limited). Each mouse received analgesia (carprofen; $5 \mathrm{mg} / \mathrm{kg}$, sc) on the day of operation. E2 benzoate (E2B) treatments were as follows. Each animal was injected on days 4-5 following OVX with $50 \mu \mathrm{l}$ of $0.25 \mu \mathrm{g}$ E2B in sesame oil, followed on day 6 with $1.50 \mu \mathrm{g}$ E2B and used for experiments on day 7. High-circulating (proestrous) levels of E2 were verified by the uterine weights $(>100 \mathrm{mg})$ at the time of death. Other OVX animals did not receive E2B, but equal volume $(50 \mu \mathrm{l})$ of sesame oil.

\section{Immunocytochemistry (ICC)}

Female Kiss $1^{\text {Cre }}$ mice or Female Kiss $1^{\text {CreGFP }:: G n R H^{G F P}}$ mice, with injection of ChR2-mCherry in the $A R H$, or AVPV/PeN were prepared for ICC as follows: coronal hypothalamic blocks (2-3 $\mathrm{mm}$ each) were fixed by immersion in $4 \%$ paraformaldehyde, cryoprotected in $30 \%$ sucrose solution, frozen at $-55^{\circ} \mathrm{C}$, sectioned coronally on a cryostat at $20 \mu \mathrm{m}$, and thaw-mounted on Superfrost Plus slides (Thermo Fisher Scientific). Sections were 
rinsed in PB $(0.1 \mathrm{~m}$ phosphate buffer, $\mathrm{pH} 7.4)$ for at least $30 \mathrm{~min}$. Next, sections were incubated with normal serum corresponding to the host for the secondary antiserum (5\% normal serum with $0.3 \%$ Triton X-100 in PBS for $30 \mathrm{~min}$ ), rinsed in PB and then incubated for $48 \mathrm{~h}$ at $4^{\circ} \mathrm{C}$ in rabbit or goat polyclonal antiserum against mCherry (1:10 000; ab167453 Abcam Inc or Biorbyt, respectively). Some sections were double-labeled for mCherry and GFP using combined mCherry (1:10000; rabbit) and biotinylated GFP (1:5000; goat) antibodies to illustrate co-expression of mCherry in Kiss $1^{\text {Cre-GFP }}$ neurons or projections of mCherry/Kiss1 fibers onto GFP-expressing GnRH neurons. Brain sections were also reacted with rabbit polyclonal antisera against kisspeptin, $\mathrm{GnRH}$, oxytocin (OT), or vasopressin using the Caraty kisspeptin antibody (no. 564; 1:2500; Franceschini et al., 2006), GnRH antibody (EL-14; 1:5000; Ellinwood et al., 1985), OT antibody (1:5000; Morris et al., 1980) or arginine vasopressin antibody (AVP; 1:5000; Dave et al., 1985) together with the mCherry antibody produced in goat described above. The specificity of these antisera has been documented previously (Ellinwood et al., 1985; Rønnekleiv et al., 1990; Franceschini et al., 2006). After rinsing, sections stained for mCherry were incubated in goat-antirabbit IgG antibody conjugated to Alexa Fluor 594 (1:500; Jackson ImmunoResearch). Sections stained for dual mCherry and kisspeptin, GnRH, OT, or AVP were first incubated for 2-3 $\mathrm{h}$ at room temperature with biotinylated bovine anti goat $(1: 500)$ and next with a mixture of streptavidin-Alexa Fluor 594 (1:2500) and goat-antirabbit IgG antibody conjugated to Alexa 488 (1:1000; Jackson ImmunoResearch). Following a final rinse overnight, slides were coverslipped with gelvatol containing the anti-fading agent, 1,4-diazabicyclo(2,2)octane (DABCO; Sigma-Aldrich; Grachev et al., 2016). We also attempted to stain for dynorphin and vGluT2 in the PVH and CART in the DMH to study Kiss1 inputs to these neurons. However, we were not able to consistently detect cell bodies in these brain regions, although we were able to detect dynorphin cells in the ARH, SON, and the striatum. It should be noted that most studies of dynorphin cells in the PVH in mice are based on using Pdyn-Cre animals (Shah et al., 2014). Therefore, we used singlecell RT-PCR (scRT-PCR) to identify Pdyn, Slc17a6 (Vglut2), or Cart mRNA following whole-cell recording (see below).

\section{Widefield Imaging}

Photomicrographs of GFP or mCherry labeling were initially acquired using a Nikon E800 fluorescent microscope (Eclipse E800; Nikon Instruments) equipped with a fiber illuminator (Intensilight C-HGFI; Nikon Instruments) and a high-definition digital microscope camera head (DS-Fi1; Nikon Instruments) interfaced with a PC-based camera controller (DS-U3; Nikon Instruments).

\section{Confocal imaging}

Confocal micrographs were acquired using one of three Zeiss AxioObserver inverted laser scanning confocal microscopes. The Zeiss LSM 780 was mounted on a motorized stand and equipped with water immersion $20 \times$ and $40 \times(0.8$ and 1.2 numerical aperture, respectively) apochromatic objectives. For mCherry/Cy3 or mCherry/ Alexa Fluor 594, 561-nm excitation was provided by a DPSS laser and detection was in the 585- to 681-nm range. GFP/Alexa Fluor 488 was excited with a $488 \mathrm{~nm}$ Argon laser and detection was in the 502- to $571-\mathrm{nm}$ range. For super-resolution images, we used both a Zeiss LSM 880 and 980 confocal microscope equipped with Fast AiryScan detector. The LSM 880 was equipped with argon and DPSS lasers for 488- and 561-nm excitation, respectively. The LSM 980 was equipped with 488 diode $(10 \mathrm{~mW})$ and 561 DPSS lasers (10 mW). For the green channel, bandpass filters for $420-480$ and $495-550 \mathrm{~nm}$ were used. The red channel used a $570-$ to $620-\mathrm{nm}$ bandpass and a $645-$ $\mathrm{nm}$ lowpass filter. Both systems used a GaAsP photomultiplier tube for detection, but the LSM 880 used Airyscan 1 (eight channels) and the LSM 980 used Airyscan 2 (32 channels). Following capture, images underwent Airyscan deconvolution in Zen Black/Blue software (Zeiss) to produce super-resolution images $(74 \mathrm{~nm} /$ pixel) before tiles were stitched together to produce a single Z-stack. Maximum intensity projections and initial Brightness/Contrast adjustments were made in FIJI (ImageJ) before saving a high resolution RGB tif version of the image. Final adjustments and cropping were made in Adobe Photoshop.

\section{Close contacts}

Immunofluorescence was captured using a Zeiss PlanApochromat $20 \times 0.8 \mathrm{NA}$ air objective, $1.5 \times \mathrm{zoom}$, a resoIution of $3048 \times 3048$ per tile, $10 \%$ tile overlap, and at a $z$-increment of $0.3-0.6 \mu \mathrm{m}$. Clearly visible immunoreactive green somata in each region were numbered in Adobe Illustrator and the presence of close contacts by (Kiss1) ChR2-mCherry fibers determined. Full Z-stack images were loaded in Zen Software (Zeiss). Close contacts were considered to be present when fibers contoured to cells and proximity was sufficiently close as to leave no intervening black pixels. Even with super-resolution ( $74 \mathrm{~nm}$ effective resolution), synapses cannot be resolved, but close proximity was reflected in the presence of yellow pixels when examining a single focal plane. Sections from at least three different mice underwent confocal analysis for the presence of close contacts. The percentage of close contacts for each animal were used to create a group average and standard error of the mean to give a qualitative assessment of typical innervation (Schindelin et al., 2012). The number of mice per group as well as the total close contacts and cells in each group are listed.

Additional image processing was performed using FIJI (ImageJ), Adobe Photoshop CC (Adobe Systems), and Zen (Zeiss, RRID:SCR_013672) software. Maximum intensity projections of z-stacks containing 10-50 optical images are presented unless otherwise specified. Brightness and contrast have been adjusted to aid in the visualization of Kiss1 neuronal projections. 
Table 1: Primer table

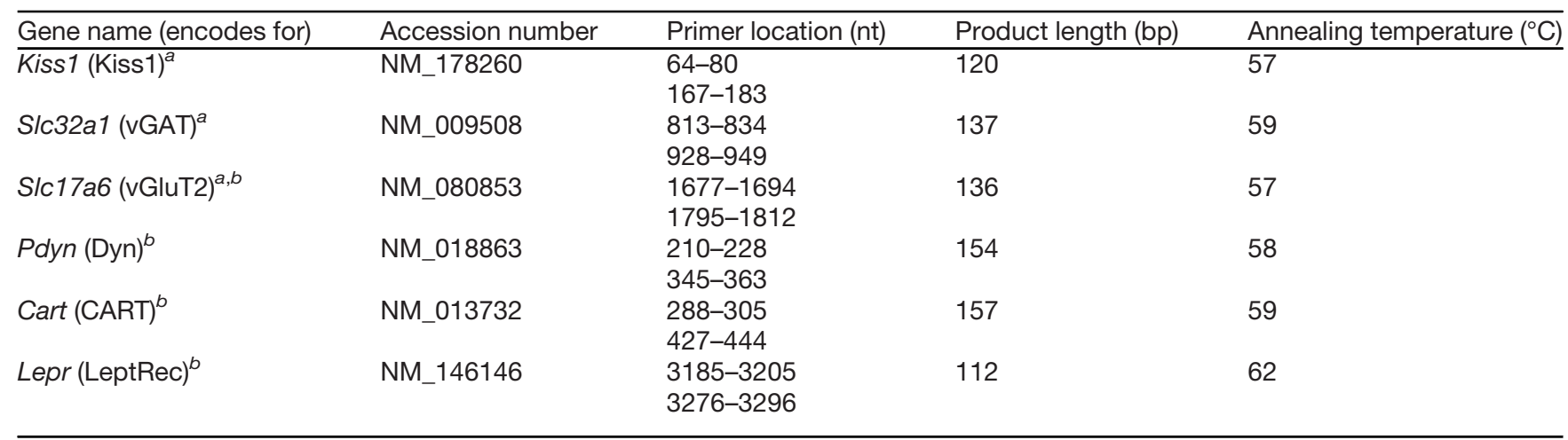

${ }^{a}$ primers used for identifying dispersed single neurons.

${ }^{b}$ primers used for identifying single neurons after electrophysiological recording.

\section{Electrophysiology}

Having identified Kiss $1^{\mathrm{AVPV} / \mathrm{PeN}}$ and $\mathrm{Kiss} 1^{\mathrm{ARH}}$ fiber inputs to $\mathrm{PVH}$ and $\mathrm{DMH}$ neurons, we were interested to explore potential functional interactions. Therefore, Kiss1 ${ }^{\text {Cre }}$ (V2) animals were used for Cre-dependent ChR2mCherry injections and subsequent optogenetic analysis of Kiss1 inputs to PVH and DMH neurons. The recordings were done blindly, the cell content harvested following the whole-cell recordings and the cell identified using ScRTPCR (see below). Fourteen to $21 \mathrm{~d}$ before each experiment, Kiss $1^{\text {Cre }}$ female or male mice ( $>60 \mathrm{~d}$ old) received bilateral AVPV/PeN or ARH injections of a Cre-dependent AAV (serotype 1) vector encoding ChR2 fused to mCherry fluorescent protein (AAV-EF1 $\alpha$-DIO-ChR2:mCh). Coronal brain slices containing the $\mathrm{PVH}$ or $\mathrm{DMH}$ from gonadectomized E2B or oil-treated AAV-EF1 $\alpha$-DIO-ChR2:mCh-injected $\mathrm{Kiss} 1^{\mathrm{Cre}}$ mice in AVPV/PeN or ARH, respectively, were prepared using established techniques. Whole-cell, patch recordings were performed in voltage clamp and current clamp using an Olympus BX51W1 upright microscope equipped with video-enhanced, infrared-differential interference contrast (IR-DIC) and an Exfo X-Cite 120 Series fluorescence light source. Electrodes were fabricated from borosilicate glass (1.5-mm outer diameter; World Precision Instruments) and filled with a normal internal solution: 128 $\mathrm{mm}$ potassium gluconate, $10 \mathrm{~mm} \mathrm{NaCl}, 1 \mathrm{~mm} \mathrm{MgCl}_{2}, 11 \mathrm{~mm}$ EGTA, $10 \mathrm{~mm}$ HEPES, $2 \mathrm{~mm}$ ATP, and $0.25 \mathrm{~mm}$ GTP $(\mathrm{pH}$ was adjusted to $7.3-7.4$ with $1 \mathrm{~N} \mathrm{KOH}, 290-300 \mathrm{mOsm}$ ) or for measurement of IPSCs, patch pipettes were filled with a high chloride solution: $140 \mathrm{~mm} \mathrm{KCl,} 10 \mathrm{~mm}$ HEPES, 0.1

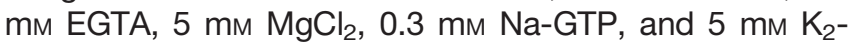
ATP, $\mathrm{pH}$ was adjusted to 7.3-7.4 with $1 \mathrm{~N} \mathrm{KOH}, 290-300$ mOsm. Pipette resistances ranged from 3 to $5 \mathrm{M} \Omega$. In whole-cell configuration, access resistance was $<20$ $\mathrm{M} \Omega$; access resistance was $80 \%$ compensated. For optogenetic stimulation, a light-induced response was evoked using a light-emitting diode (LED) 470-nm blue light source controlled by a variable $2 \mathrm{~A}$ driver (ThorLabs) with the light path delivered directly through an Olympus $40 \times$ water-immersion lens. LED light pulses were 5-10 $\mathrm{ms}$ long and $0.2-0.9 \mathrm{~mW}$ at the surface of the tissue. Electrophysiological signals were amplified with an Axopatch $200 \mathrm{~A}$ and digitized with Digidata 1322A
(Molecular Devices, Foster City, CA), and the data were analyzed using p-Clamp software (version 9.2, Molecular Devices). The liquid junction potential was corrected for all data analysis. All drugs used in the electrophysiological experiments were purchased from Tocris Bioscience unless otherwise specified. DL-amino-5-phosphonovaleric acid (AP5; $50 \mathrm{~mm}$ ), 6-cyano-7-nitroquinoxaline-2, 3-dione (CNQX; $10 \mathrm{~mm}$ ), CGP55845 (10 mM), and 4-aminopyridine (4-AP; $500 \mathrm{~mm}$ ) were dissolved in $\mathrm{H}_{2} \mathrm{O}$. Tetrodotoxin (TTX) was purchased from Alomone Labs (1 $\mathrm{mm}$ ) and dissolved in $\mathrm{H}_{2} \mathrm{O}$. Tetraethylammonium chloride (TEA; 7.5) was purchased from Sigma-Aldrich and dissolved in aCSF. Picrotoxin (100 mM) was dissolved in dimethyl sulfoxide (DMSO). Aliquots of the stock solutions were stored as appropriate until needed for experiments.

\section{SCRT-PCR}

After electrophysiological recording, the cytosol of recorded cells was harvested and used for post hoc identification. Briefly, the recorded cells were harvested with gentle suction to the recording pipette and expelled into a siliconized $0.5-\mathrm{ml}$ microcentrifuge tube containing a solution of $1 \times$ Invitrogen Superscript III buffer, $15 \mathrm{U}$ of Rnasin (Promega), $10 \mathrm{~mm}$ of dithiothreitol (DTT) and diethylpyrocarbonate (DEPC)-treated water in a total of $5 \mu \mathrm{l}$ for a single cell. cDNA synthesis was performed on single cells in a $20-\mu$ reaction volume using Superscript II reverse transcriptase (Invitrogen) according to manufacturer's proto$\mathrm{col}$ and stored at $-20^{\circ} \mathrm{C}$. Controls included water blanks, and hypothalamic tissue RNA reacted with and without reverse transcriptase (-RT). Primers were designed using Clone Manager software (Sci Ed Software) to cross at least one intron-exon boundary and optimized for single-cell mRNA determination following whole-cell recording (see Table 1). scPCR was performed on 3-4 $\mu$ l of cDNA in a $30 \mu \mathrm{l}$ reaction volume using GoTaq polymerase (Invitrogen) combined with Taqstart Antibody (Takara) according to manufacturer's protocol; then amplified 50 cycles using a C1000 Thermal Cycler (Bio-Rad). The PCR product was visualized with ethidium bromide on a $2 \%$ agarose gel. 

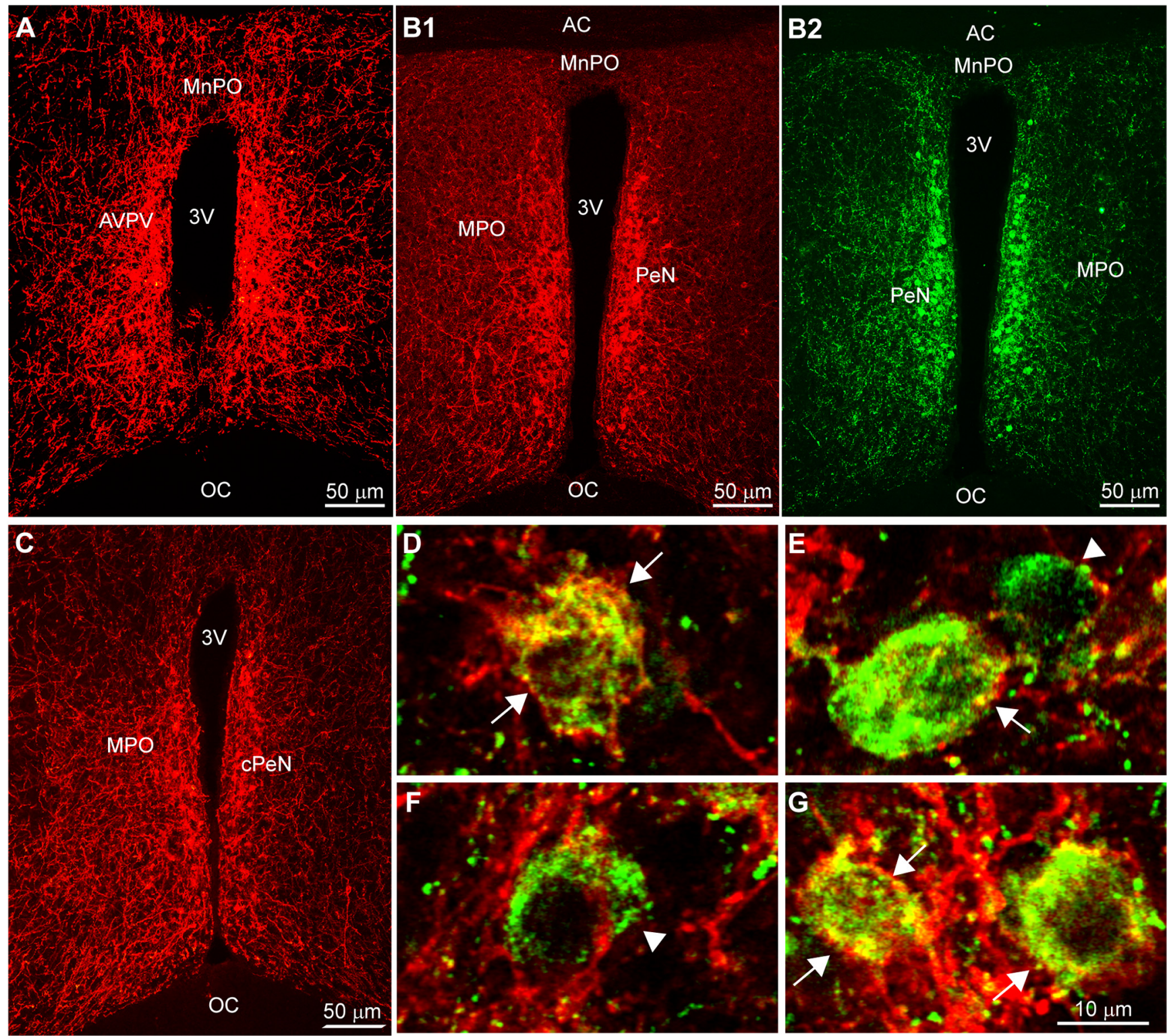

Figure 1. Kiss $1^{\text {Cre }}$-dependent ChR2-mCherry expressing neurons in the AVPV-PeN are also positive for kisspeptin. $\boldsymbol{A}, \boldsymbol{B 1}, \mathbf{C}$, Lowmagnification, fluorescent images of Cre-driven ChR2-mCherry expression enhanced with ICC for mCherry. mCherry-labeled Kiss1 cells are distributed within the AVPV $(\boldsymbol{A})$ and in a more narrow vertical band along the third ventricle (3V) from rostral to caudal PeN $(B 1, C)$. The section in $\mathbf{B 1}$ was also immunostained for kisspeptin (B2). D-G, Composite confocal images demonstrating that cells exhibiting Cre-driven mCherry expression are co-labeled by the Caraty kisspeptin antibody (green; arrows), but not all immunoreactive kisspeptin neurons also expressed ChR2-mCherry (arrow-head), likely because of incomplete coverage/infection by injected virus. AC, anterior commissure; AVPV, anteroventral periventricular nucleus; MnPO, median preoptic nucleus; MPO, medial preoptic nucleus; PeN, periventricular nucleus; OC, optic chiasm; 3V, third ventricle). Scale bars: $50 \mu \mathrm{m}(\boldsymbol{A}-\boldsymbol{C})$ and $10 \mu \mathrm{m}(\boldsymbol{D}-\mathbf{G})$.

\section{Results}

\section{AVPV/PeN injections of ChR2-mCherry}

We delivered bilateral injections of AAV-Ef1 $\alpha$-DIOmCherry:ChR2 to the AVPV/PeN of Kiss $1^{\text {Cre }}(n=5)$ or

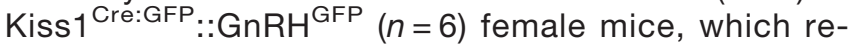
sulted in labeled Kiss1 cell bodies bilaterally from the AVPV rostrally to the caudal part of the PeN (Fig. $1 A-C)$. ICC was used to enhance the Cre-dependent labeling and aid in visualization. In order to confirm specificity of Cre-driven mCherry expression in Kiss1 cells, several tissue sections were also co-reacted with a kisspeptin antibody (Fig. 1B1,B2; Table 3). While the majority of neurons displayed co-localization of both fluorophores, several neurons were green-only (Fig. 1E,F). This would indicate that while the AAV/Cre-driven labeling of Kiss1 cells is specific (Nestor et al., 2016), the antibody directed against kisspeptin labeled a greater percentage of the total Kiss $1^{\mathrm{AVPV} / \mathrm{PeN}}$ population. Additionally, no mCherrylabeled cells were detected in the $\mathrm{ARH}$, indicating that any projections noted in these animals originated 

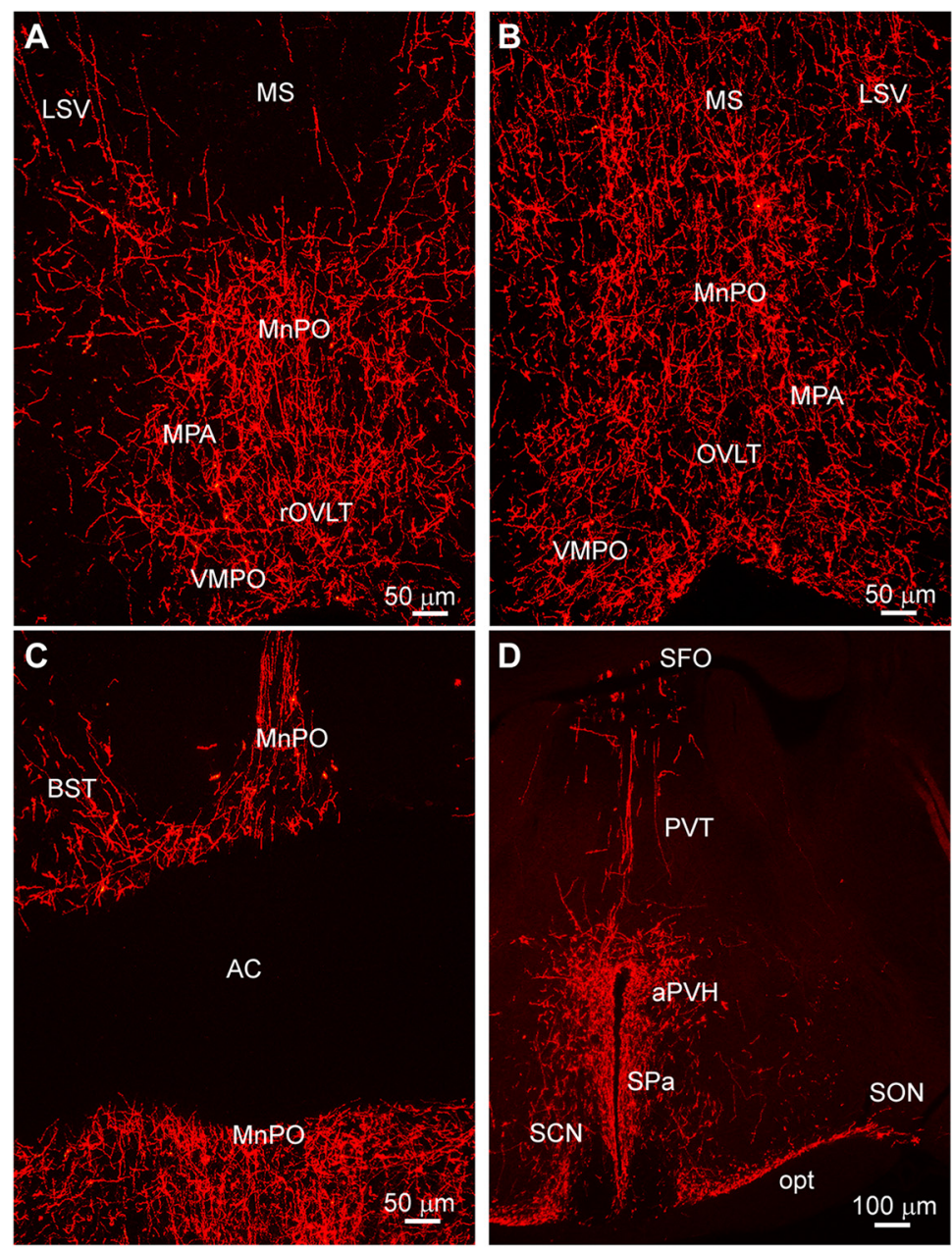

Figure 2. Kiss $1^{A V P V / P e N}$ projections densely innervate different nuclei within the POA-AH. $\boldsymbol{A}-\boldsymbol{C}$, Representative sections from rostral to caudal POA illustrating Kiss $1^{\mathrm{Cre}}:$ :ChR2-mCherry fiber-projections from POA Kiss1 neurons to different nuclei including the

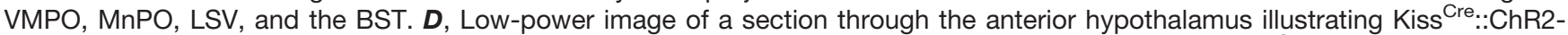
mCherry fiber-projections to the aPVH, PVT, SFO, and SON. Note the SCN is essentially devoid of Kiss $1^{\mathrm{Cre}}$ :ChR2-mCherry fiberinput. LSV, lateral septal nucleus, ventral; MS, medial septal nucleus; MnPO, median preoptic nucleus; MPA, medial POA; VMPO, ventromedial preoptic nucleus; OVLT, organum vasculosum lamina terminalis; BST, bed nucleus stria terminalis; SFO, subfornical organ; PVT, paraventricular nucleus thalamus; aPVH, anterior paraventricular nucleus, hypothalamus; SPa, subparaventricular zone; SCN, suprachiasmatic nucleus; opt, optic tract; SON, supraoptic nucleus. Scale bars: $50 \mu \mathrm{m}(\boldsymbol{A}-\boldsymbol{C})$ and $100 \mu \mathrm{m}(\boldsymbol{D})$.

from the AVPV/PeN. These Kiss $1^{\mathrm{AVPV} / \mathrm{PeN}}$ neurons were found to send extensive fiber projections rostrally to various $P O A$ regions including the ventromedial preoptic (VMPO) and medial POA (MPA) from rostral to caudal, organum vasculosum of lamina terminalis (OVLT), and the median preoptic nucleus (MnPO; Fig. 2A-C). Interestingly, both the VMPO and $\mathrm{MnPO}$ are known to be involved in temperature regulation (Tan et al., 2016; Abbott and Saper, 2017).

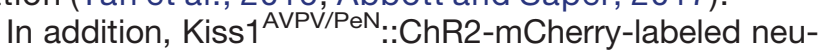
ronal fibers extended dorsolaterally toward the ventrolateral septal areas (LSV), medial septum (MS), and bed nucleus stria terminalis (BST; Fig. $2 A-C$ ). At the level of the suprachiasmatic nucleus (SCN), fibers extended dorsally toward the hypothalamic anterior parvocellular $\mathrm{PVH}$ (aPVH) and further dorsal into the paraventricular nucleus of the thalamus (PVT). ChR2-mCherry-labeled fibers were also observed in the subfornical organ (SFO; Fig. 2D).
Although ChR2-mCherry fibers surrounded the SCN, the SCN itself appeared to lack fiber-input from these rostral Kiss $1^{\text {AVPV/PeN }}$ neurons (Fig. 2D). The ChR2-mCherry-labeled Kiss 1 fibers also extended laterally along the optic tract (opt) as well as close to and, in some cases, into the medial part of the SON (Fig. 2D). In addition, fibers originating in the Kiss $1^{\mathrm{AVPV} / \mathrm{PeN}}$ innervated the PVH and the subparaventricular zone (SPa) from rostral to caudal with the densest projections to the medial parts of the PVH (Fig. 3). Further caudal the fiber-projections were particularly dense in the $\mathrm{DMH}$ from rostral to caudal, whereas the $\mathrm{VMH}$ was essentially devoid of ChR2-mCherry-labeled Kiss $1^{\text {AVPV } / P e N}$ fibers (Fig. 4). ChR2-mCherry fibers also reached parts of the ARH but did not extend into the median eminence (ME; Fig. 4). It should be emphasized that this projection pattern was similar in all the Kiss $1^{\mathrm{AVPV} / \mathrm{PeN}}$ ::ChR2-mCherry injected females $(n=11)$. 


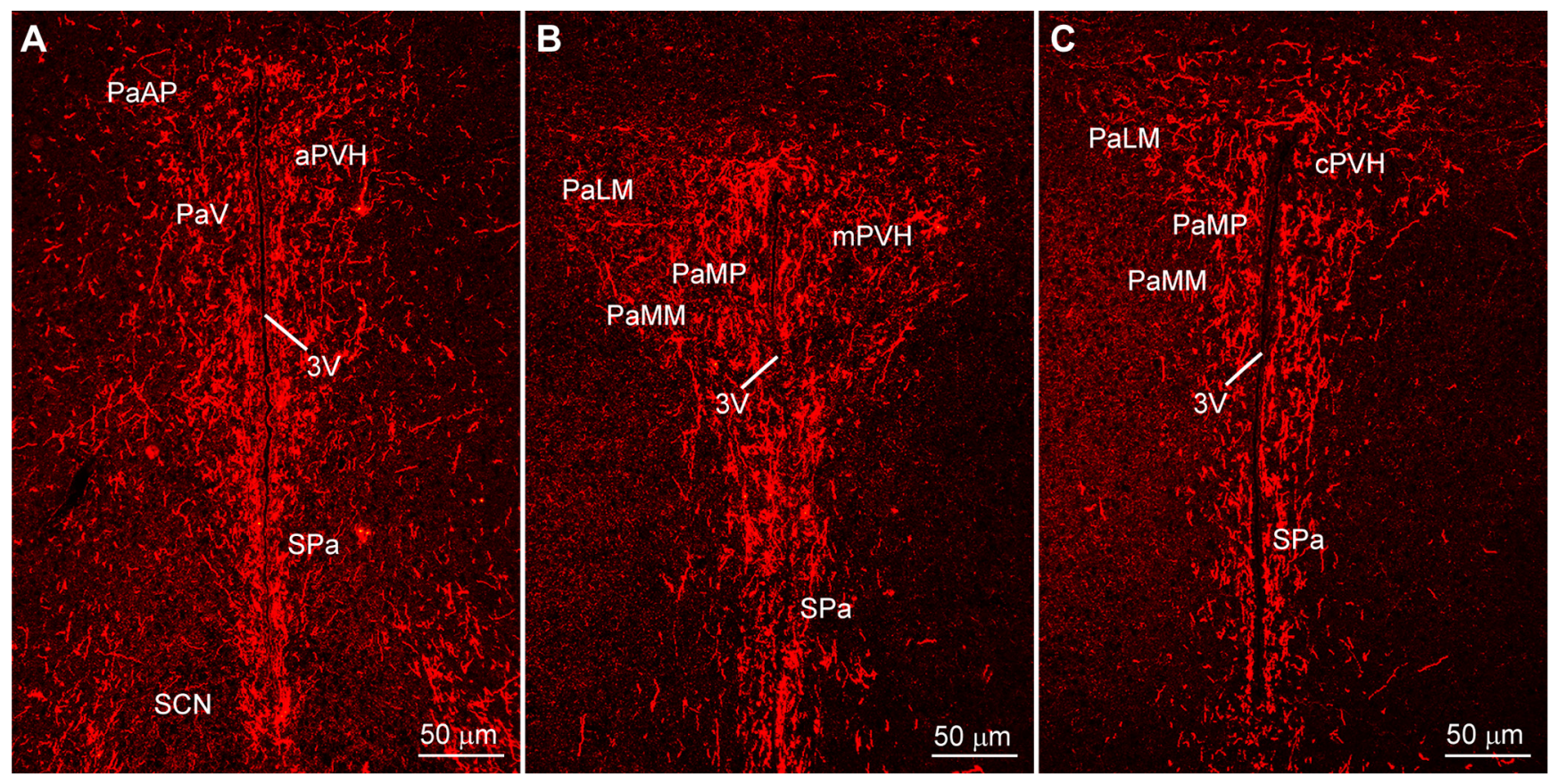

Figure 3. Kiss1 ${ }^{\mathrm{AVPV} / \mathrm{PeN}}:$ :ChR2-mCherry projections to the PVH. $\boldsymbol{A}-\boldsymbol{C}$, ChR2-mCherry fluorescent images of the rostral to caudal progression through the anterior hypothalamus showing dense innervation of the PVH by Kiss $1^{\mathrm{AVPV} / \mathrm{PeN}}$ fibers. Scale bar: $50 \mu \mathrm{m}$. $\mathrm{PaAP}$, paraventricular hypothalamus anterior parvicells; PaV, paraventricular hypothalamus ventral; PaLM, paraventriclular hypothalamus lateral magnocells; PaMM, paraventricular hypothalamus medial magnocells; PaMP, paraventricular hypothalamus medial parvicells. For further abbreviations, see legend to Figure 2.

\section{ARH injections of ChR2-mCherry}

Bilateral injections of Cre-dependent AAV-Ef1 $\alpha$-DIOmCherry:ChR2 into the ARH of Kiss ${ }^{\text {Cre }}(\mathrm{OVX} ; n=6)$ or Kiss $1^{\mathrm{Cre}}:: \mathrm{GnRH}{ }^{\mathrm{GFP}}$ (OVX, $n=5$ ) female mice resulted in labeled Kiss 1 cell bodies bilaterally throughout the ARH from rostral to caudal (Fig. 5A-C). Cell bodies were clearly seen clustered in the more rostral and middle portions of $\mathrm{ARH}$ (rARH and $\mathrm{mARH}$ ). Kiss1 neurons become more scattered in the caudal ARH (cARH) with a small number residing in the $\mathrm{DMH}$ (Fig. $5 \mathrm{C}$ ). We found that the majority of ChR2-mCherry labeled ARH neurons were double- labeled for kisspeptin (Fig. 5D,E). In addition, ChR2mCherry fibers were observed in the internal zone of the $\mathrm{ME}$, connecting Kiss $1^{\mathrm{ARH}}$ neurons on both sides of the ventricle. Kiss $1^{\mathrm{ARH}}$ fibers also interact with $\mathrm{GnRH}$ fibers in the ME area (see below).

Unlike Kiss $1^{\mathrm{AVPV} / \mathrm{PeN}}$ neurons, Kiss $1^{\mathrm{ARH}}$ neurons provided only sparse input to the rostral POA where the majority of $\mathrm{GnRH}$ neurons are located (Fig. $6 A, B$ ). Importantly, no labeled Kiss1 cell bodies were detected in the AVPV/PeN area (Fig. 6C,D), and therefore, all projections seen in these sections came from the ARH Kiss1
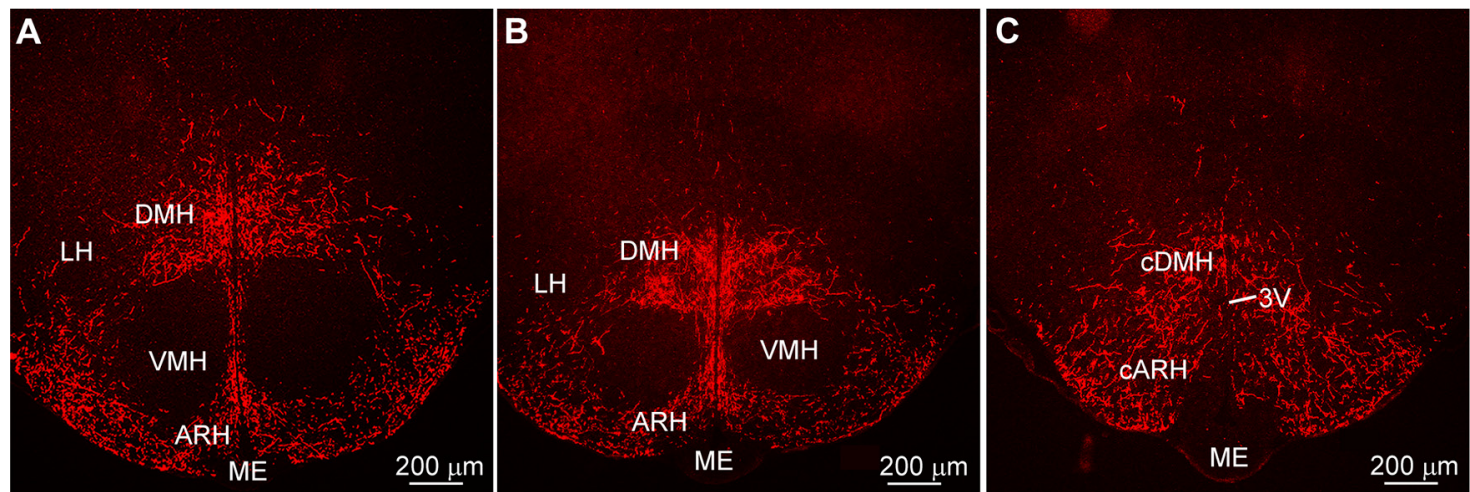

Figure 4. Kiss $1^{\mathrm{AVPV} / \mathrm{PeN}} \mathrm{ChR} 2-\mathrm{mCherry}$ projections to the DMH. $\boldsymbol{A}-\boldsymbol{C}$, ChR2-mCherry fluorescent images of the rostral to caudal progression through the basal hypothalamus showing dense innervation of the DMH by Kiss $1^{\text {AVPV/PeN }}$ fibers. Note the extensive fiber-projection to the $\mathrm{DMH}$ from rostral to caudal, and the ventral fiber-bundle to the $\mathrm{ARH}$, but not the $\mathrm{ME}$ or the VMH. Scale bar: $200 \mu \mathrm{m}$. DMH, dorsomedial hypothalamic nucleus; $\mathrm{LH}$, lateral hypothalamic area; VMH, ventromedial hypothalamic nucleus; $\mathrm{ARH}$, arcuate hypothalamic nucleus; ME, median eminence. 

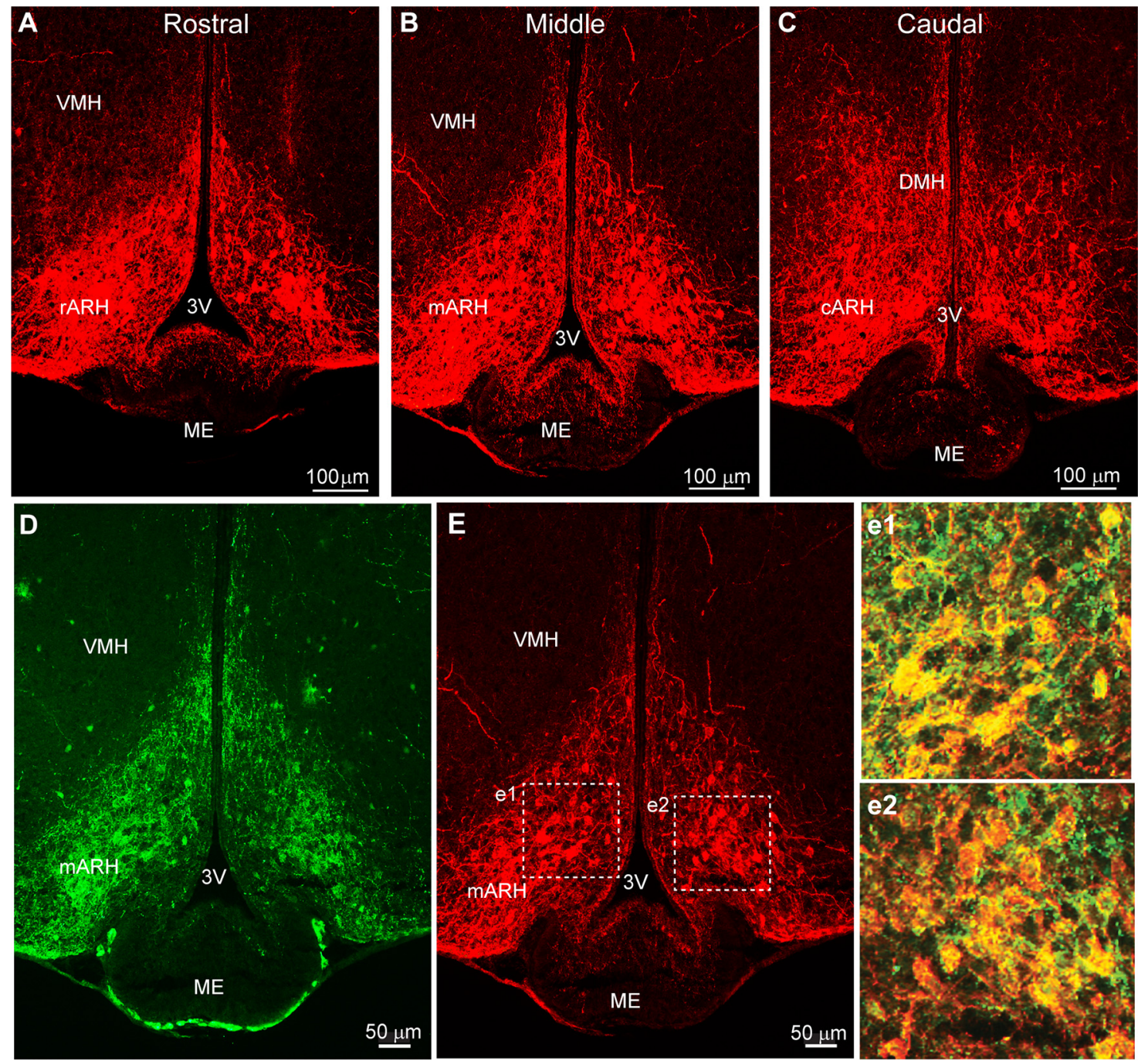

Figure 5. Kiss $1^{\mathrm{Cre}}$-dependent $\mathrm{ChR2}-\mathrm{mCherry}$ expressing neurons in the ARH. $\boldsymbol{A}-\boldsymbol{C}$, Fluorescent images of the basal hypothalamus displaying Cre-driven expression of ChR2-mCherry-labeled neurons within the arcuate nucleus (ARH) from rostral to caudal. Labeled fibers are primarily located within the internal zone of the ME. The section in $\boldsymbol{E}$ was also immunostained for kisspeptin $(\boldsymbol{D})$. e1, e2, Composite confocal images demonstrating that cells exhibiting Cre-driven mCherry expression are co-labeled with a kisspeptin antibody. For abbreviations, see legend to Figure 4. Scale bars: $100 \mu \mathrm{m}(\boldsymbol{A}-\boldsymbol{C})$ and $50 \mu \mathrm{m}(\boldsymbol{D}, \boldsymbol{E})$.

population. However, Kiss $1^{\mathrm{ARH}}$ neurons sent extensive ChR2-mCherry fiber projections to more caudal regions in the POA, primarily to the AVPV, MPO, and the PeN (see also Qiu et al., 2016), and the projections extended dorsolaterally to the BST (Fig. 6C-E). In contrast to Kiss $1^{\text {AVPVI }}$ PeN projections, Kiss $1^{\mathrm{ARH}}$ ChR2-mCherry-labeled fibers were sparse in the VMPO and the MnPO, areas known to be involved in temperature regulation (Fig. 6A-E; Tan et al., 2016; Abbott and Saper, 2017). At the level of the rSCN, ChR2-mCherry-labeled fibers from Kiss $1^{\mathrm{ARH}}$ neurons appeared to traverse the SCN (Fig. 6F), but no direct input to the SCN could be identified at any level. ChR2mCherry fibers were also traced dorsally to the SPa and into the full extent of the PVH from rostral to caudal (Fig. 7). In addition, labeled fibers from Kiss $1^{\mathrm{ARH}}$ neurons were detected in the $\mathrm{DMH}$, particularly in the more caudal regions (Fig. 8). Notably, Kiss $1^{A R H}$ fiber-input to the $\mathrm{DMH}$ was considerably less than that from Kiss $1^{\mathrm{AVPV} / \mathrm{PeN}}$ neurons (Fig. 4 vs Fig. 8). Again, this projection pattern was consistent for all of the Kiss $1^{\mathrm{ARH}}:$ : ChR2-mCherry injected females $(n=11)$.

\section{Kiss $1^{\mathrm{AVPV} / \mathrm{PeN}}$ and Kiss $1^{\mathrm{ARH}}$ interactions with GnRH neurons and fibers}

We imaged sections with super-resolution confocal microscopy to search for close contacts or interactions between Kiss1 fibers and GnRH neurons. In order to visualize $\mathrm{GnRH}$ neurons and their projections, we co-reacted slides with the EL14 antibody or GFP antibody (see Materials and Methods). Our analysis of $\mathrm{GnRH}$ neurons in $\mathrm{OVX}+\mathrm{E}$ females found that the extensive ChR2-mCherry projections from Kiss $1^{\mathrm{AVPV} / \mathrm{PeN}}$ neurons (Fig. 9A) formed close contacts with the majority (Table 2) of GnRH neurons located within the diagonal band (DB), MS, OVLT/ POA area rostrally to the anterior hypothalamus caudally 

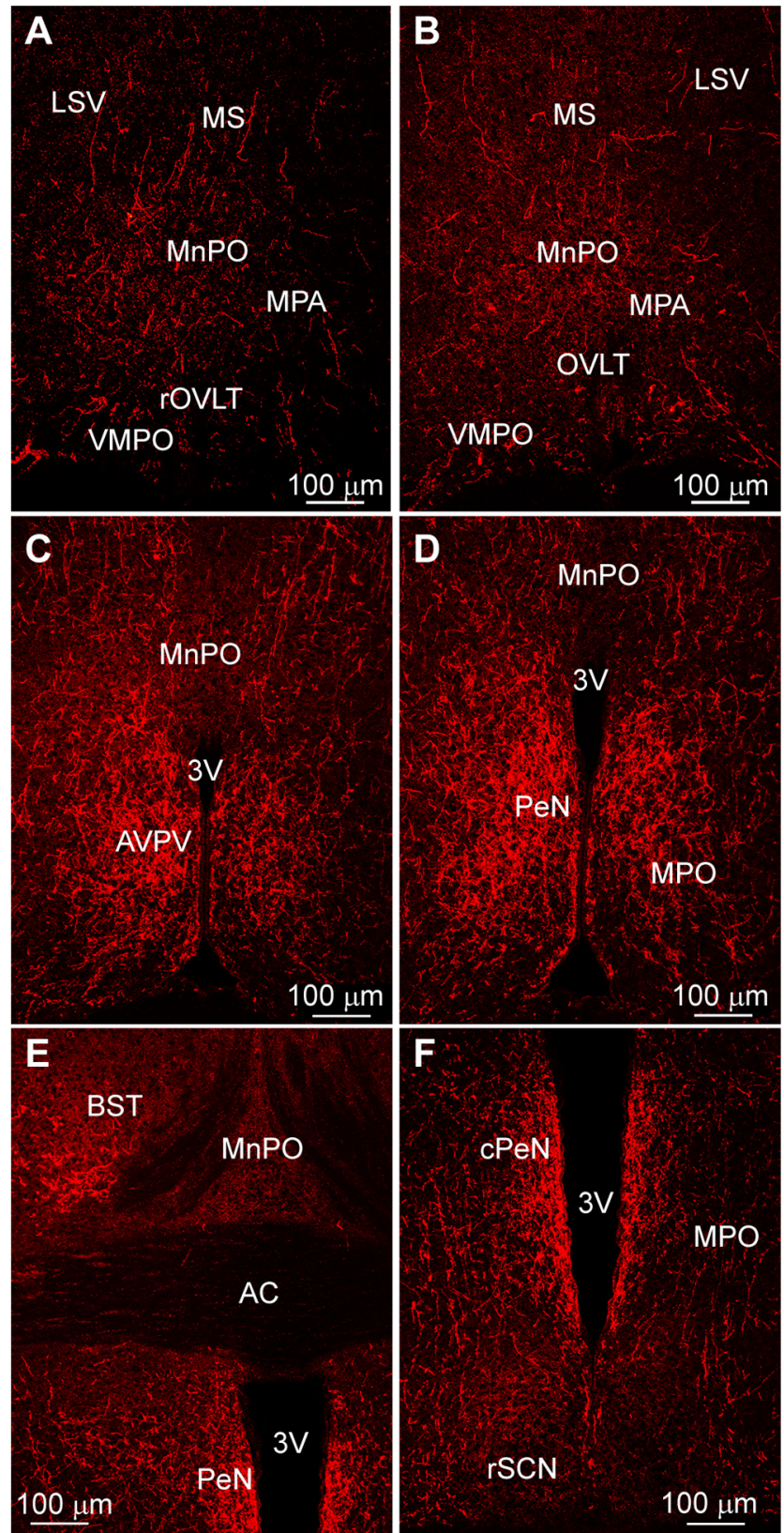

Figure 6. Kiss $1^{\mathrm{ARH}}:$ :ChR2-mCherry projections to the POA. $\boldsymbol{A}$, $\boldsymbol{B}$, Fluorescent images of the Cre-driven ChR2-mCherry projections from Kiss $1^{\mathrm{ARH}}$ neurons to the rostral POA, a region where most of the $\mathrm{GnRH}$ neurons are located. $\boldsymbol{C}-\boldsymbol{F}$, Kiss $1^{\mathrm{ARH}}$ neurons send extensive projections to the AVPV, PeN, MPO, and BST. Note the slight fiber-input to the VMPO, OVLT, MPA, and $\mathrm{MnPO}$, rostral brain regions important for reproduction and temperature regulation. For abbreviations, see legend to Figure 2. Scale bar: $100 \mu \mathrm{m}$.

(Fig. 9a1,a2; Table 2). In contrast, Kiss $1^{\mathrm{ARH}}$ neurons provided sparse fiber-input into the rostral brain regions described above (Fig. 9B) and onto only a few $\mathrm{GnRH}$ neuronal cell bodies (Fig. 9b1,b2; Table 2). In addition, when using the EL14 ( $\mathrm{GnRH})$ antibody to better visualize $\mathrm{GnRH}$ processes in addition to soma, there were indications of close contacts between Kiss $1^{\mathrm{ARH}}$ fibers and proximal GnRH dendrites (Fig. 9Cc1,c2).
Kiss $1^{\text {AVPV/PeN }}$ neurons provided negligible input to the ME (Figs. 4, 10A), and as such, few Kiss $1^{\text {AVPV/PeN }}$ fibers were seen in close proximity to $\mathrm{GnRH}$ fibers in this region (Fig. 10B). Clearly a primary target of the Kiss $1^{\text {AVPVIPeN }}$ neurons are the GnRH neuronal somas (Fig. 9A) and not the fiber-terminals in the ME (Fig. 10A,B). Conversely, Kiss $1^{\mathrm{ARH}}$ neurons project throughout the $\mathrm{ME}$, including the external layer, although the major projections were directly onto the lateral palisade zone (LPZ) where $\mathrm{GnRH}$ fibers are highly concentrated (Figs. 5, 10C-F; King et al., 1982; Rønnekleiv and Kelly, 1986). The maximum intensity of the projection (Fig. 10C) gives the impression of a significant interaction between Kiss $1^{\mathrm{ARH}}$ and $\mathrm{GnRH}$ fibers; however, when viewed in a single confocal plane (Fig. $10 D)$, the ChR2-mCherry and GnRH fibers mostly appeared to run in parallel (white arrow). Still, yellow pixels designating close contacts of mCherry and GFP could be seen laterally where the $\mathrm{GnRH}$ fibers consolidate (Fig. $10 E$ ) and also immediately before entering the ME (Fig. $10 F)$. Thus, the occasional close contacts between Kiss $1^{\mathrm{ARH}}$ and $\mathrm{GnRH}$ fibers were primarily observed at the lateral interface of the $\mathrm{ARH}$ with the stalk ME and most likely represent non-synaptic points of close interaction/ proximity between Kiss $1^{\mathrm{ARH}}$ and $\mathrm{GnRH}$ fibers (Uenoyama et al., 2011; Liu et al., 2021).

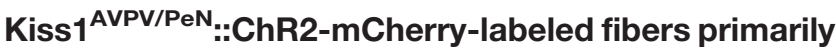 onto OT neurons in the SON}

ChR2-mCherry-labeled fibers from Kiss $1^{\mathrm{AVPV} / \mathrm{PeN}}$ neurons were found to extend laterally toward the medial parts of the SON (Fig. 2D). As both AVP and OT neurons are found in the SON, we used confocal microscopy in conjunction with double-label ICC to determine whether Kiss1 fibers made contact with either population. Superresolution images confirmed that fibers did reach and were present in the SON (Fig. 11 $A a, B b)$. Through analysis of the confocal Z-stack we were also able to identify close contacts made onto SON neurons. Specifically, yellow pixels, where Kiss1 fibers met with cell bodies, were seen on roughly one-third of AVP neurons (Table 2), which occurred more frequently with OT neurons (Table 2). However, the close contacts that were seen onto VP neurons appeared more rarely (Fig. 11Aa), whereas those onto OT neurons were more extensive (Fig. 11Bb). Therefore, the number of contacts with AVP neurons is likely an over estimation, but we are more confident that Kiss $1^{\text {AVPV/PeN }}$ fibers make close contact with OT neurons. We did attempt to examine close contacts between Kiss $1^{\mathrm{ARH}}$ fibers and OTNP neurons; however, these projections barely reached the SON (Fig. 11C). Even the more medial AVP neurons, relative to the location of OT SON neurons, lacked significant contacts (Fig. 11Cc). The absence of fibers in the SON was seen even with "on target" ARH injections and strong ChR2-mCherry expression (Fig. 11D). Therefore, we did not proceed further with this particular analysis.

\section{Kiss $1^{\mathrm{AVPV} / \mathrm{PeN}}$ and Kiss $1^{\mathrm{ARH}}$ projections to AVP neurons in the SCN}

While OT neurons are not present in the SCN, AVP neurons are known to reside in the SCN, particularly the shell region (Fig. 12A). Kiss $1^{\mathrm{AVPV} / \mathrm{PeN}}:$ :ChR2-mCherry-labeled 

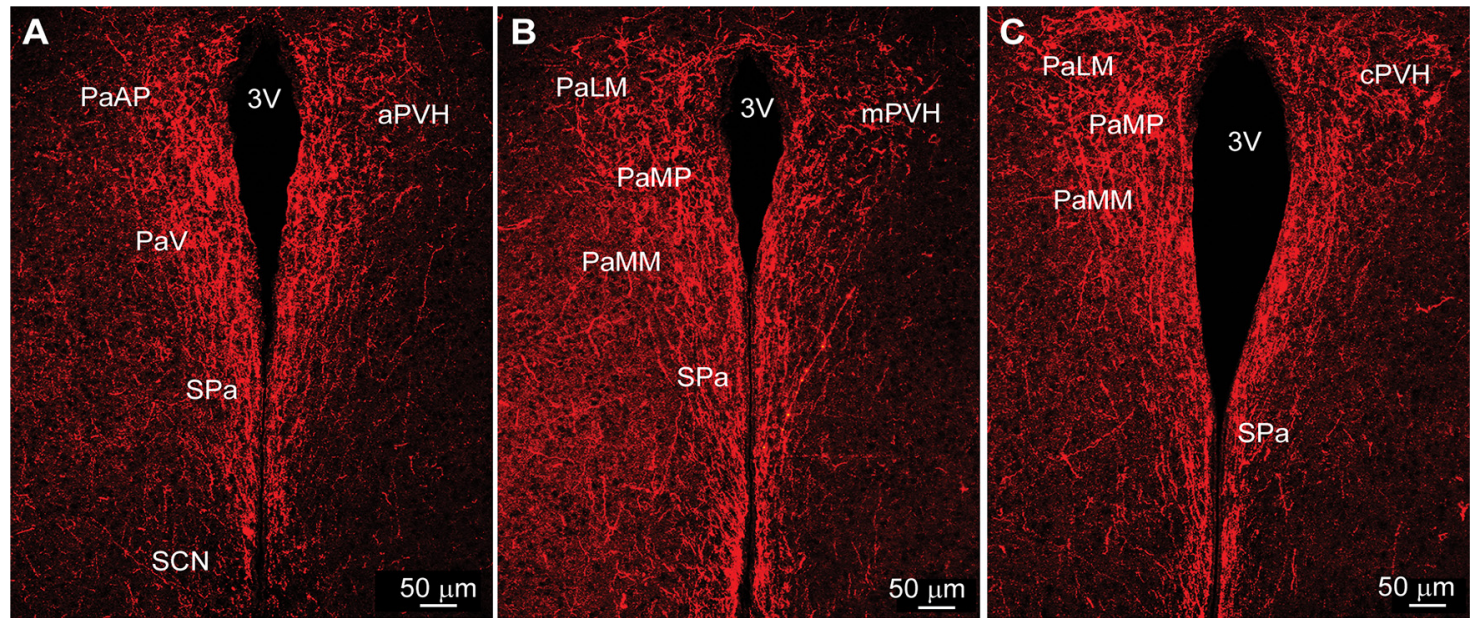

Figure 7. Kiss $1^{\mathrm{ARH}}::$ ChR2-mCherry projections to the PVH. $\boldsymbol{A}-\boldsymbol{C}, \mathrm{ChR} 2-\mathrm{mCherry}$ fluorescent images of the rostral to caudal progression through the anterior hypothalamus showing dense fiber-input to the $\mathrm{PVH}$ by Kiss $1^{\mathrm{ARH}}$ fibers. For abbreviations, see legend to Figures 2, 3. Scale bar: $50 \mu \mathrm{m}$.

fibers largely avoided the core of the SCN (Figs. 2D, 3A), but appeared to contact the most dorso-medial AVP cells (Fig. 12a). Similarly, Kiss $1^{\mathrm{ARH}}$ ::ChR2-mCherry-labeled fibers also tended to avoid the SCN, but a subset of fibers could be seen passing through the rostral SCN (Fig. 12B).
Examination of single confocal planes did reveal a few potential close contacts (Fig. 12b), but the large number of local AVP processes made it difficult to distinguish between Kiss1 fibers passing through the SCN and those actually making close contact.
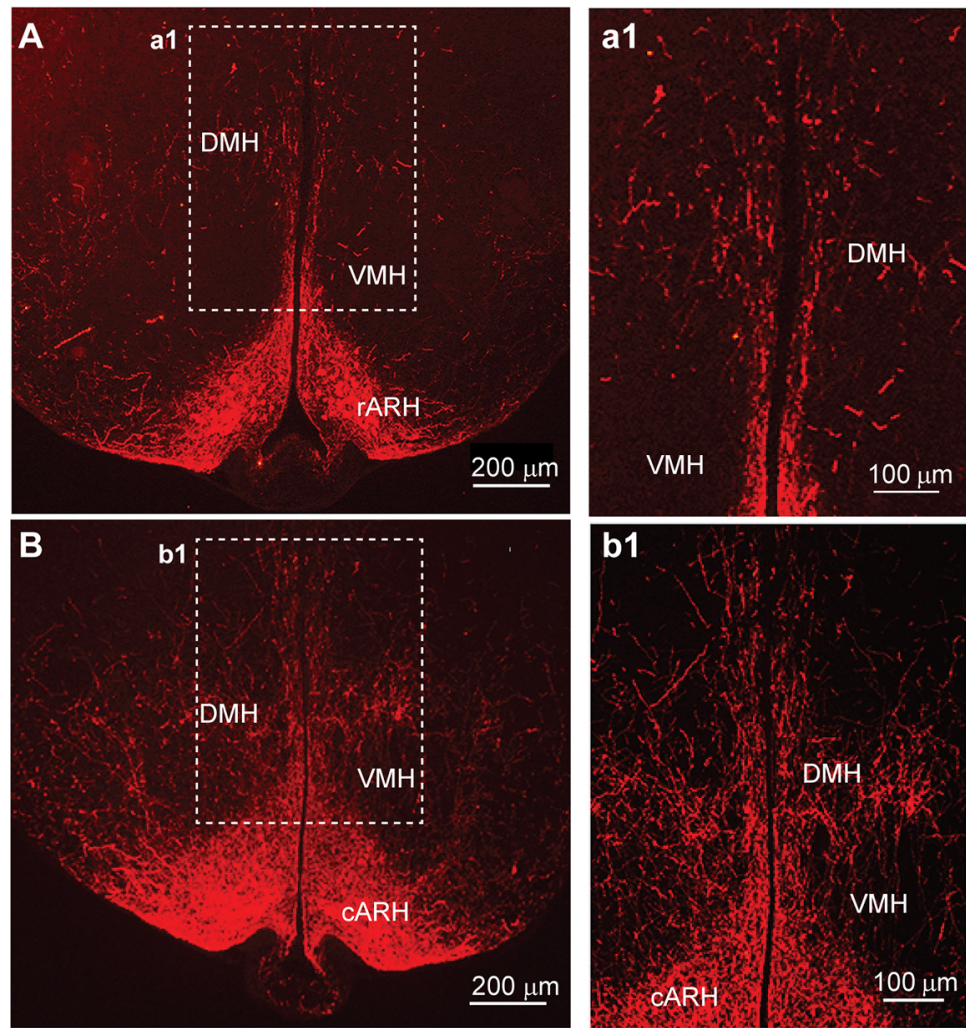

Figure 8. Kiss $1^{\mathrm{ARH}}$ ::ChR2-mCherry projections to the $\mathrm{DMH}$. $\boldsymbol{A}$, Fluorescent image of ChR2-mCherry fiber-input to the rostral $\mathrm{DMH}$ by Kiss $1^{A R H}$ neurons. Inset (a1) shows a higher magnification of the stippled area in $\boldsymbol{A}$. $\boldsymbol{B}$, Fluorescent image of ChR2-mCherry fiber-input to the caudal DMH by Kiss $1^{\mathrm{ARH}}$ neurons. Inset (b1) shows a higher magnification of the stippled area in $\boldsymbol{B}$. DMH, dorsomedial hypothalamic nucleus; $\mathrm{LH}$, lateral hypothalamic area; $\mathrm{VMH}$, ventromedial hypothalamic nucleus; $\mathrm{ARH}$, arcuate hypothalamic nucleus; ME, median eminence. Scale bars: $200 \mu \mathrm{m}(\boldsymbol{A}, \boldsymbol{B})$ and $100 \mu \mathrm{m}(\mathbf{a 1}, \boldsymbol{b} \mathbf{1})$. 

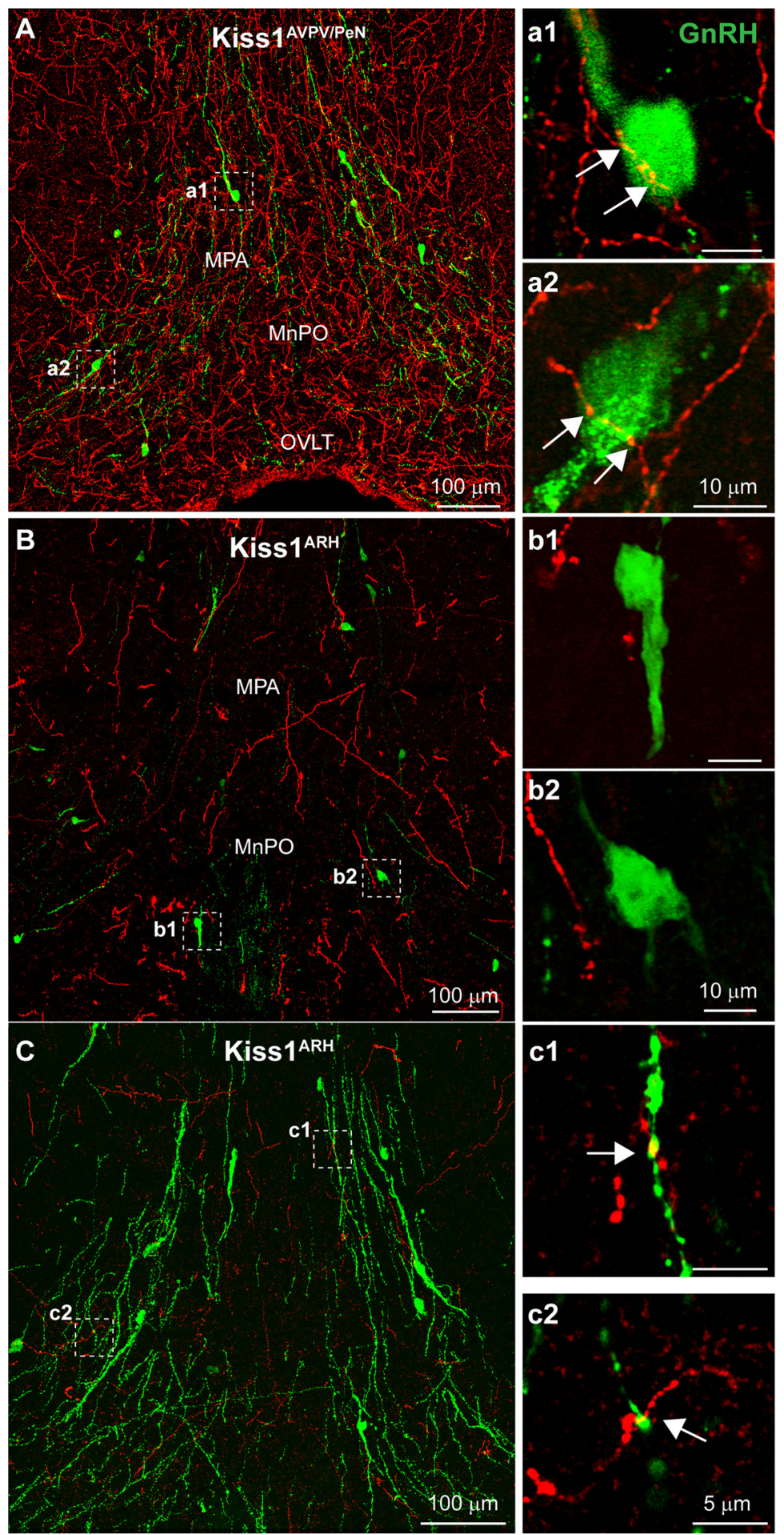

Figure 9. Differential innervation of $\mathrm{GnRH}$ neurons by AVPV/PeN and ARH Kiss1 populations. Confocal image montages of immunolabeled ChR2-mCherry Kiss1 fibers and GFP GnRH neurons. A, Kiss1 fibers from the AVPV/PeN are dense in the MPA where $\mathrm{GnRH}$ neurons are located. a1, a2, Single optical slice from regions highlighted by white boxes in $\boldsymbol{A}$ show that $\mathrm{GnRH}$ neurons receive close contacts (white arrows) from Kiss $1^{\mathrm{AVPV} / \mathrm{PeN}}$ fibers. $\boldsymbol{B}$, Kiss1 fibers from the ARH are scarce in the MPA. $\boldsymbol{b} 1, \boldsymbol{b} \mathbf{2}$, Single optical slice $(1 \mu \mathrm{m}$ thick) from regions marked in $\boldsymbol{B}$. In stark contrast, few Kiss 1 fibers from the ARH are present in the MPA or make close apposition with GnRH neurons. C, Confocal image montages of immunolabeled ChR2-mCherry Kiss1 fibers and GnRH neurons identified with the EL14 GnRH antibody, with extensive label of GnRH dendrites (green). c1, c2, Single optical slice from regions highlighted by white boxes in $\mathbf{C}$ show that $\mathrm{GnRH}$ neuronal dendrites receive close contacts (white arrows) from Kiss $1^{\mathrm{ARH}}$ fibers. 
Table 2: Close contact analysis

\begin{tabular}{|c|c|c|c|c|c|c|c|}
\hline Injection & Region & Target & Group average & Group SEM & Mice $(n)$ & Total CC & Total cells \\
\hline$\overline{\text { AVPV }}$ & PaLM & OT & $33.3 \%$ & $10.2 \%$ & 3 & 34 & 120 \\
\hline AVPV & PV/PaMP & OT & $55.6 \%$ & $8.9 \%$ & 4 & 80 & 126 \\
\hline AVPV & PaMM & AVP & $38.1 \%$ & $7.2 \%$ & 6 & 74 & 287 \\
\hline AVPV & PV/PaMP & AVP & $62.2 \%$ & $6.6 \%$ & 6 & 77 & 125 \\
\hline AVPV & SON & AVP & $27.7 \%$ & $5.0 \%$ & 3 & 63 & 229 \\
\hline $\mathrm{ARH}$ & PaLM & OT & $32.1 \%$ & $4.1 \%$ & 4 & 47 & 151 \\
\hline $\mathrm{ARH}$ & PaMM & OT & $25.1 \%$ & $2.5 \%$ & 4 & 42 & 172 \\
\hline $\mathrm{ARH}$ & PV/PaMP & OT & $48.3 \%$ & $5.7 \%$ & 6 & 75 & 146 \\
\hline $\mathrm{ARH}$ & PaLM & AVP & $33.2 \%$ & $4.8 \%$ & 4 & 86 & 258 \\
\hline $\mathrm{ARH}$ & PaMM & AVP & $35.9 \%$ & $6.7 \%$ & 5 & 68 & 208 \\
\hline $\mathrm{ARH}$ & PV/PaMP & AVP & $68.6 \%$ & $9.5 \%$ & 5 & 62 & 88 \\
\hline
\end{tabular}

Female Kiss $1^{\mathrm{Cre}}$ or Kiss ${ }^{\mathrm{Cre}}:: \mathrm{GnRH}{ }^{\mathrm{GFP}}$ mice were injected with AAV1-ChR2-mCh into either the AVPV/PeN or ARH. Brain sections were processed for doublelabel ICC to enhance the mCherry signal and visualize potential postsynaptic targets of Kiss1 fibers using confocal microscopy. The PVH was divided into the dorsolateral PaLM, ventromedial PaMM, and the medial PV/PaMP regions. GnRH neurons in the rostral forebrain (POA), comprising the DB, MS, POA, and anterior hypothalamus were analyzed. Additionally, the supraoptic nucleus (SON) was also examined. The postsynaptic populations included OT, AVP, and GnRH neurons.

\section{Kiss1 input onto OT neurons in the PVH}

OT neurons are located in different subdivisions of the $\mathrm{PVH}$, including the paraventricular medial parvicellular (PaMP) regions, as well as dorsolateral (PaLM) and ventromedial magnocellular (PaMM) parts, as previously described (Biag et al., 2012). In the aPVH, the OT neurons are scattered throughout the nucleus with a small number of cells found near the third ventricle (Fig. 13A,C). Using super-resolution confocal microscopy, we assessed the presence of close contacts made between ChR2mCherry labeled Kiss1 fibers from either the AVPV/PeN (Fig. 13A,a1-a3) or the ARH (Fig. 13C,c1-c3). We found that Kiss $1^{\mathrm{AVPV} / \mathrm{PeN}}$ fibers made close appositions with an average of $42.1 \%(99 / 235$ cells; $n=2)$ and Kiss $1^{\text {ARH }}$ with $25.1 \%(58 / 231$ cells; $n=3)$ of the OT neurons in the aPVH. Further caudal, the ChR2-mCherry fiber-input to the PVH thins and spreads laterally into "wings" of the PVH (Figs. $3,7)$. Here, in the $c P V H$, Kiss $1^{\mathrm{AVPV} / \mathrm{PeN}}$ mCherry fibers were primarily found along the ventricle with fewer fibers extending laterally (Fig. 13B) and, therefore, the periventricular/medial population of OT neurons (PV/PaMP; Table 2) received more close contacts than the dorsolateral PaLM (Table 2) and ventromedial PaMM (Table 2). In comparison, Kiss $1 \mathrm{ARH}$ fibers were more evenly distributed throughout the CPVH (Fig. 13D) and show a similar likelihood of contacting either the PV/PaMP (Table 2), PaLM (Table 2), or PaMM (Table 2) OT neurons.

\section{Kiss1 input onto AVP neurons in the PVH}

Similar to OT neurons, AVP neurons were also observed in the periventricular (PV) area dorsal to the SCN, the

Table 3: Key resources table

\begin{tabular}{|c|c|c|c|c|}
\hline Reagent type (species) or resou & ce additional information & Designation & Source or reference & Identifiers \\
\hline Genetic reagent ( $M$. Musculus) & Kiss1 ${ }^{\text {Cre:GFP }}$ version 2 (V2) & $\begin{array}{l}\text { Dr. Richard D. Palmiter; University of Washington; } \\
\text { PMID: } 29336844\end{array}$ & & \\
\hline Genetic reagent ( $M$. Musculus) & $G n R H^{G F P}$ & Suter et al. (2000); PMID:10614664 & & \\
\hline Genetic reagent (AAV) & AAV1-Ef1 $\alpha$-DIO-ChR2:mCherry & $\begin{array}{l}\text { Dr. Stephanie L. Padilla; University of } \\
\text { Washington; PMID: } 25429312\end{array}$ & & \\
\hline Antibody & Anti-mCherry (rabbit polyclonal) & Abcam & Abcam: ab167453 RRID:AB_2571870 & $(1: 10000)$ \\
\hline Antibody & Anti-mCherry (goat polyclonal) & Biorbyt & Biorbyt: orb11618 RRID:AB_2687829 & $(1: 10000)$ \\
\hline Antibody & Anti-kisspeptin (rabbit polyclonal) & $\begin{array}{l}\text { Dr. Alain Caraty Universite Francois- } \\
\text { Rabelais Tours; PMID:16621281 }\end{array}$ & No. 564 RRID: AB_2622231 & $(1: 2500)$ \\
\hline Antibody & Anti-OT (rabbit polyclonal) & Morris et al. (1980); PMID:7448278 & & $(1: 5000)$ \\
\hline Antibody & Anti-GnRH (rabbit polyclonal) & Ellinwood et al. (1985); PMID:3887335 & EL-14 RRID:AB_2715535 & $(1: 5000)$ \\
\hline Antibody & Anti-AVP (rabbit polyclonal) & Dave et al. (1985); PMID: 2992912 & & $(1: 5000)$ \\
\hline Antibody & Biotin-SP AffiniPure bovine anti-goat lgG & Jackson ImmunoResearch Labs & Jackson: 805-065-180 RRID: AB_2340876 & $(1: 500)$ \\
\hline Antibody & Biotin anti-GFP (goat polyclonal) & Abcam & Abcam: ab6658 RRID: AB_305631 & $(1: 5000)$ \\
\hline Antibody & Alexa Fluor 594-streptavidin & Jackson ImmunoResearch Labs & Jackson: 016-580-084 RRID: AB_2337250 & $(1: 2500)$ \\
\hline Antibody & Goat anti-rabbit IgG Alexa Fluor 594 & Thermo Fisher Scientific & Catalog \#A-11037 RRID: AB_2534095 & $(1: 500)$ \\
\hline Antibody & Goat anti-rabbit IgG Alexa Fluor 488 & Thermo Fisher Scientific & Catalog \#A-11034 RRID: AB_2576217 & $(1: 1000)$ \\
\hline Software & ZEN digital imaging for light microscopy & Zeiss & RRID:SCR_013672 & \\
\hline
\end{tabular}



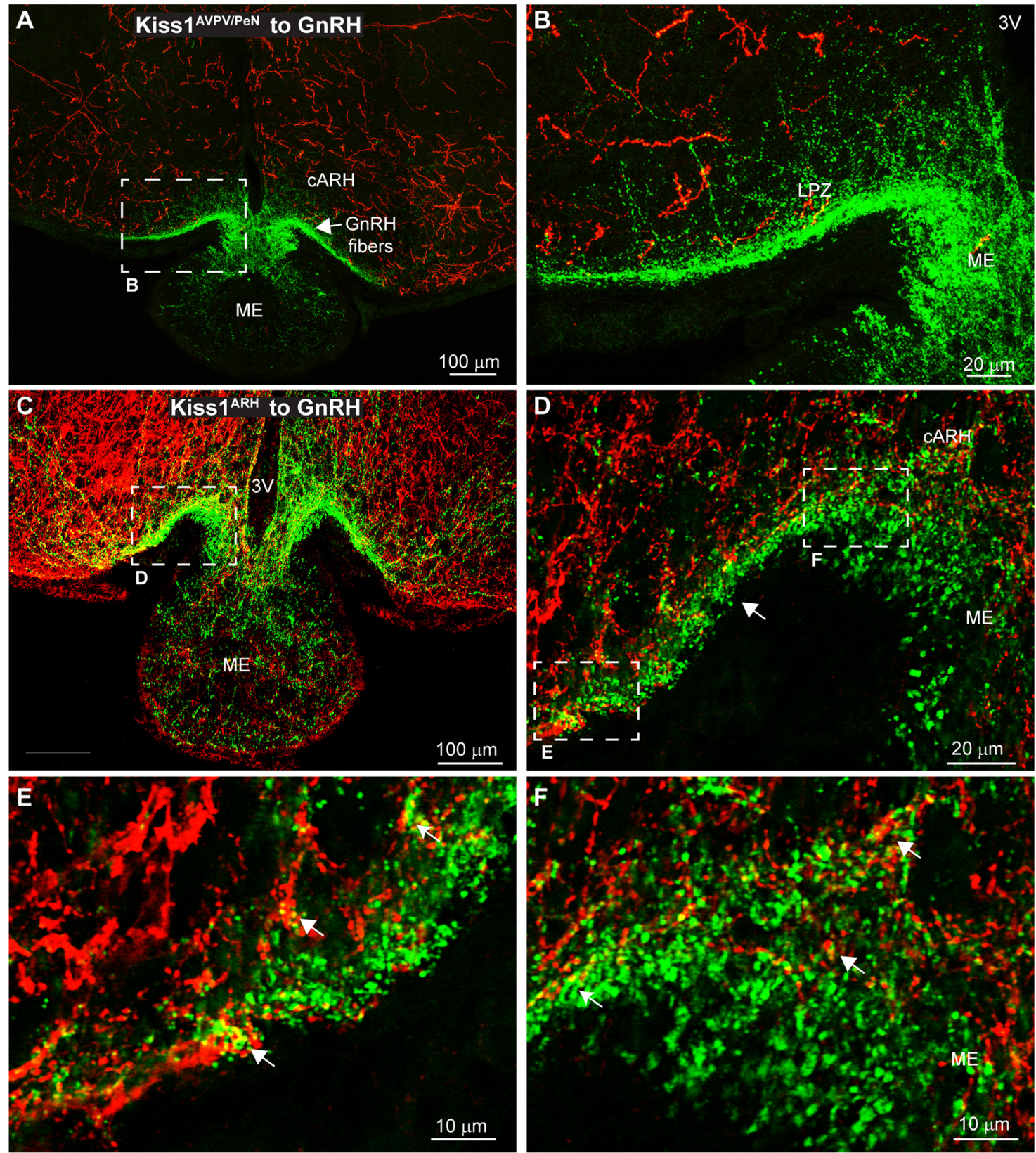

Figure 10. Interactions between $\mathrm{GnRH}$ and Kiss1 fibers in the ME. Confocal image montages of double label ICC that show Kiss1 fibers (ChR2-mCherry) originating from either the AVPV/PeN or ARH. GnRH fibers (green) enter the ARH laterally and along the 3V from the POA before entering the ME. $\boldsymbol{A}$, Kiss $1^{\text {AVPV/Pen }}$ fibers are diffuse in the ARH and do not enter the ME. $\boldsymbol{B}$, Expanded view of the dashed box from $\boldsymbol{A}$. Few Kiss $1^{\mathrm{AVPV} / \mathrm{PeN}}$ fibers reach the ventral surface where GnRH fibers concentrate, which would suggest interactions are unlikely. $\boldsymbol{C}$, Confocal image montage displays staining of $\mathrm{Kiss} 1^{\mathrm{ARH}}$ cell bodies and projections in the $\mathrm{cARH}$ and $\mathrm{ME}$. $\boldsymbol{D}$, Single optical slice $(1 \mu \mathrm{m}$ thick) of the region outlined in $\mathbf{C}$. GnRH fibers enter the ARH laterally (left) to briefly form a bundle (white arrow) that runs along the ventral surface before dispersing in the ME. $\boldsymbol{D}$, Expanded view of the left white box in $\boldsymbol{C}$. The occasional presence of yellow pixels and lack of black pixels between Kiss $1^{\mathrm{ARH}}$ and $\mathrm{GnRH}$ fibers suggests the presence of interactions. $\boldsymbol{E}, \boldsymbol{F}$, Expanded view of the regions from the white boxes in $\boldsymbol{D}$. As the $\mathrm{GnRH}$ fibers enter the ME the lack of black pixels between Kiss $1^{\mathrm{ARH}}:: \mathrm{ChR} 2-\mathrm{mCherry}$ and $\mathrm{GnRH}$ fibers and presence of yellow pixels suggest close contacts (white arrows) between fibers.

$\mathrm{PaAp}$ area in the aPVH and further caudal in different subdivisions of the $\mathrm{CPVH}$, including the PaMP parvicellular regions, as well as dorsolateral (PaLM) and ventromedial (PaMM) magnocellular parts. However, AVP neurons tended to be found more laterally, with only a few neurons located near the ventricle (Fig. 14). Kiss $1^{\mathrm{ARH}}$ fibers made close contact with roughly a third of PaLM (Table 2) and PaMM (Table 2) AVP neurons. Despite the smaller AVP population in $\mathrm{PV} / \mathrm{PaMP}$, the majority there received close contacts from Kiss $1^{\mathrm{ARH}}$ neurons (Table 2). Kiss $1^{\mathrm{AVPV} / \mathrm{PeN}}$ fibers into the PVH (Fig. 14C) primarily contacted the PV/ PaMP (Table 2) with the PaMM (Table 2) and PaLM (Table 

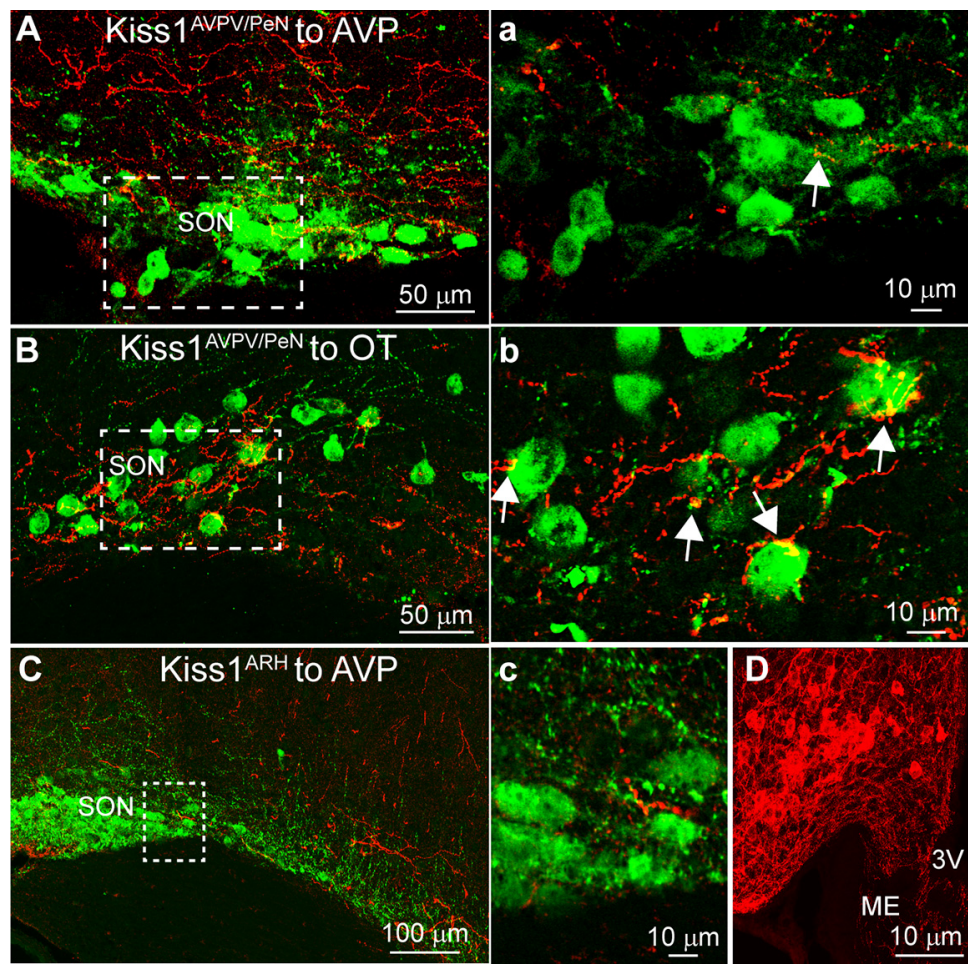

Figure 11. Kiss1 fiber projections to AVP and OT neurons in the SON. $\boldsymbol{A}$, Confocal image montage of double-label ICC that shows Kiss $1^{\mathrm{AVPV} / \mathrm{PeN}}$ fibers (ChR2-mCherry) run laterally along the ventral surface to reach the SON. A population of AVP neurons (green) are found just above and lateral to the optic tract in the SON. $\boldsymbol{a}$, Single optical slice of view from region marked by a white box in $\boldsymbol{A}$. Despite many nearby Kiss $1^{\mathrm{AVPV} / \mathrm{PeN}}$ fibers there are few indications of close contacts. $\boldsymbol{B}$, Slightly medial to the AVP neurons, a population of OT neurons is also located in the SON. $\boldsymbol{b}$. Single optical slice analysis at $1-\mu \mathrm{m}$ focal plane shows that Kiss $1^{\mathrm{AVPV} / \mathrm{PeN}}$ fibers are more likely to make contact with OT neurons and appositions are quite extensive (white arrows). $\mathbf{C}$, Kiss $1^{\mathrm{ARH}}$ fibers do not provide notable innervation of the SON. c, Single confocal plane of region marked in white box. Few if any SON AVP neurons receive close contacts. $\boldsymbol{D}$, Confocal image of mCherry-labeled Kiss1 neurons in the ARH from the same animal as in $\boldsymbol{C}$. The lack of $\mathrm{Kiss} 1^{\mathrm{ARH}}$ fibers to the SON was seen even when Kiss $1^{\mathrm{ARH}}$ neurons were strongly labeled (D).

2) receiving fewer close contacts. Clearly, ChR2-mCherry Kiss $1^{\mathrm{AVPV} / \mathrm{PeN}}$ and Kiss $1^{\mathrm{ARH}}$ fibers may contact other neurons besides those expressing OT and AVP within the $\mathrm{PVH}$, such as those expressing prodynorphin (pDyn), corticotropin-releasing factor (CRF), melanocortin-4 receptor (MC4R), and/or vGluT2, based on the distribution of these neurons within the PVH as shown using animals expressing the respective Cre recombinase (Viau and Sawchenko, 2002; Xu et al., 2013; Garfield et al., 2015). Indeed, some of these were identified using scRT-PCR of harvested neurons following whole-cell recording.

\section{Kiss $1^{A V P V / P e N}$ neurons inhibit PVH and DMH neurons via GABA release}

As a complementary approach, we did whole-cell, voltage-clamp recordings in slices from E2-treated OVX female mice, and examined evoked (photostimulated) postsynaptic currents (PSCs) in PVH and DMH neurons from Kiss $1^{\text {Cre:GFP }}$ mice that had received bilateral injections of AAV1-ChR2-mCherry into AVPV/PeN (Figs. 15, $16 A 1, A 2)$. It had been shown previously that Kiss $1^{\mathrm{AVPV} / \mathrm{PeN}}$ neurons express S/c32a1 (vGAT) and not S/c17a6 (vGluT2) mRNA in the animal model used for these experiments (Qiu et al., 2016). To confirm these data, we harvested in vitro $30 \mathrm{Kiss} 1^{\mathrm{AVPV} / \mathrm{PeN}}$ neurons from each of two OVX, E2treated Kiss 1 CreGFP females. The scRT-PCR analysis revealed that $70-80 \%$ of the harvested Kiss 1 neurons expressed S/c32a1 mRNA and only 3.3\% (two of 60) were found to express S/c17a6. Therefore, these data confirm that GABA and not glutamate is packaged into vesicles and released by Kiss $1^{\mathrm{AVPV} / \mathrm{PeN}}$ neurons in this animal model (Qiu et al., 2016).

Using a standard internal solution, whole-cell voltage clamp recordings were made in $\mathrm{PVH}$ neurons $\left(\mathrm{V}_{\text {hold }}=\right.$ $-10 \mathrm{mV}$ ). Fast outward currents were recorded in response to blue light stimulation in $23 \mathrm{PVH}$ cells (Fig. 15B). This light-induced response was abrogated $(91 \%$ blockade) with picrotoxin $(100 \mu \mathrm{m}), \mathrm{a} \mathrm{GABA}_{\mathrm{A}}$ receptor antagonist (Fig. 15C). To augment the GABA-mediated response from Kiss $1^{\mathrm{AVPV} / \mathrm{PeN}}$ neurons, we recorded an additional cohort of neurons using a high chloride internal solution $(n=10)$, which shifted $\mathrm{E}_{\mathrm{Cl}}$ and changed the GABA-mediated response from an outward to an inward current (Fig. $15 D, E)$, which was also blocked by picrotoxin (12.4 \pm 0.4 vs $140.0 \pm 34.5 \mathrm{pA}$ control, $n=3$ ). The small latency between optogenetic stimulation and postsynaptic response ( $4.5 \pm 0.3 \mathrm{~ms}, n=31)$ was suggestive of a direct connection (Felix-Ortiz et al., 2013; Holloway et al., 2013). However, to further support this supposition we blocked 


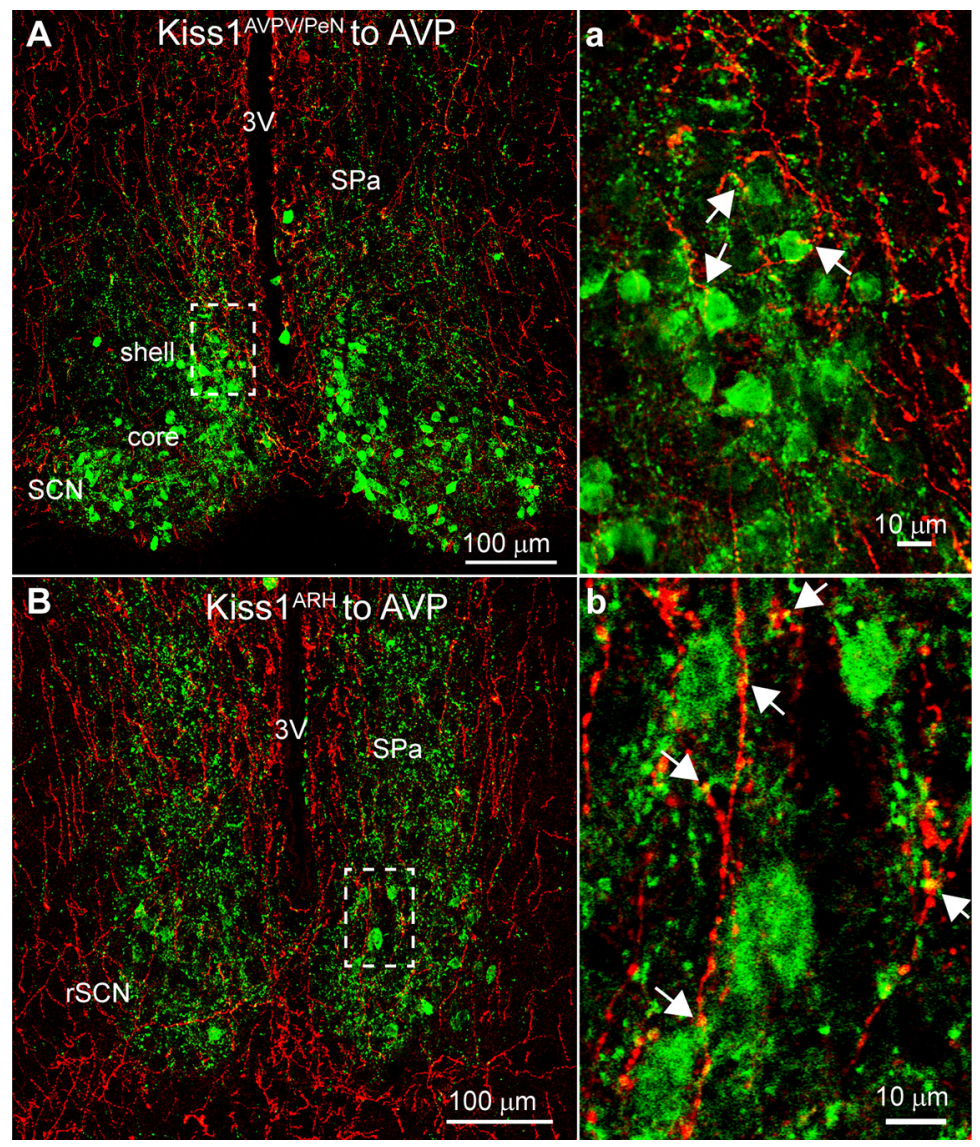

Figure 12. Kiss 1 fiber projections to AVP neurons in the SCN. A) Confocal image montage shows that Kiss $1^{\mathrm{AVPV} / \mathrm{PeN}}$ fibers (red) run along the $3 \mathrm{~V}$ and surround the SCN. Double label ICC was used to visualize AVP neurons (green) which are primarily located in the shell of the SCN. a, Although practically no Kiss $1^{\mathrm{AVPV} / \mathrm{PeN}}$ fibers enter the SCN core, when viewing a single optical plane close contacts appear to be made with some of the most external AVP neurons (white arrows). $\boldsymbol{B}$, Confocal image montage of the Kiss $1^{\mathrm{ARH}}$ fibers in the rSCN. Few AVP cells bodies are present, but ascending projections can be seen running parallel to the 3V. $\boldsymbol{b}$, Single optical slice centered on the region demarcated by the white box in $\boldsymbol{B}$. A number of Kiss $1^{\mathrm{ARH}}$ fibers pass through the SCN, potentially making close contact with AVP neurons or their fiber projections. However, the density of labeled AVP projections obscures somata and hinders analysis.

the photostimulated postsynaptic inward current with TTX (Fig. 15D) and rescued the light-induced response with the addition of $\mathrm{K}^{+}$channel blockers 4-AP and TEA (Fig. 15D; Cousin and Robinson, 2000; Petreanu et al., 2009), which is biophysical evidence for direct synaptic contact between Kiss $1^{\mathrm{AVPV} / \mathrm{PeN}}$ neurons and $\mathrm{PVH}$ parvocellular neurons. With the rescue experiment there was a twofold increase in the latency $(n=4)$ to the response because of the fact that the calcium influx into the nerve terminal is principally dependent on ChR2 when the fast sodium channels are blocked by TTX (Felix-Ortiz et al., 2013; Holloway et al., 2013).

Furthermore, in voltage clamp $\left(\mathrm{V}_{\text {hold }}=-60 \mathrm{mV}\right)$ highfrequency stimulation of Kiss $1^{\text {Cre }}$-ChR2 fibers generated a slow IPSC in PVH neurons (Fig. 15E), which was blocked by $\mathrm{GABA}_{\mathrm{B}}$ receptor antagonist CGP 55845 (1 $\mu \mathrm{m}$; Fig. 15F). The PSC responsive neurons were located dorso-medially in the $\mathrm{PVH}$ with a resting membrane potential of $-64.9 \pm 2.3 \mathrm{mV}$, an input resistance of $1.2 \pm 0.1$ $\mathrm{G} \Omega$ and a capacitance of $20.4 \pm 1.0 \mathrm{pF}(n=29)$, typical endogenous properties of parvocellular neurons (Luther and Tasker, 2000; Stern, 2001). Indeed, ten neurons were identified post hoc via scRT-PCR as expressing Vglut2 mRNA, and four neurons expressed Pdyn mRNA, two of which also expressed Vglut2 (Fig. 15G) The Pdyn PVH neurons had an input resistance of $1.6 \pm 0.4 \mathrm{G} \Omega$ and cell capacitance of $16.8 \pm 2.2 \mathrm{pF}$. The majority $(70 \%)$ of the responsive $\mathrm{PVH}$ neurons, expressed an h-current, including the Pdyn neurons (Fig. 15H), which is an endogenous characteristic of preautonomic parvocellular $\mathrm{PVH}$ neurons (Stern, 2001).

Kiss $1^{\text {AVPVIPeN }}$ neurons also inhibited DMH neurons via GABA release. Blind whole-cell patch was done on $\mathrm{DMH}$ neurons near Kiss1-ChR2:mCherry fibers (Fig. 16A2) in $\mathrm{OVX}+\mathrm{E} 2$ mice that received bilateral injections of AAV1ChR2-mCherry into the AVPV/PeN area (Fig. 16A1). Outward PSCs were reliably evoked by photostimulation and sufficiently strong enough to be measured using a standard $\mathrm{K}^{+}$gluconate internal solution $\left(\mathrm{V}_{\text {hold }}=-10 \mathrm{mV}\right)$ in $24 \mathrm{DMH}$ neurons (Fig. 16B-D). Picrotoxin was effective at blocking the currents, confirming GABAergic signaling (Fig. 16C). The parvocellular neurons displaying an inhibitory PSC had an average resting membrane potential of $-62.6 \pm 2.3 \mathrm{mV}$, input resistance of $1.5 \pm 0.2 \mathrm{G} \Omega$, and cell 

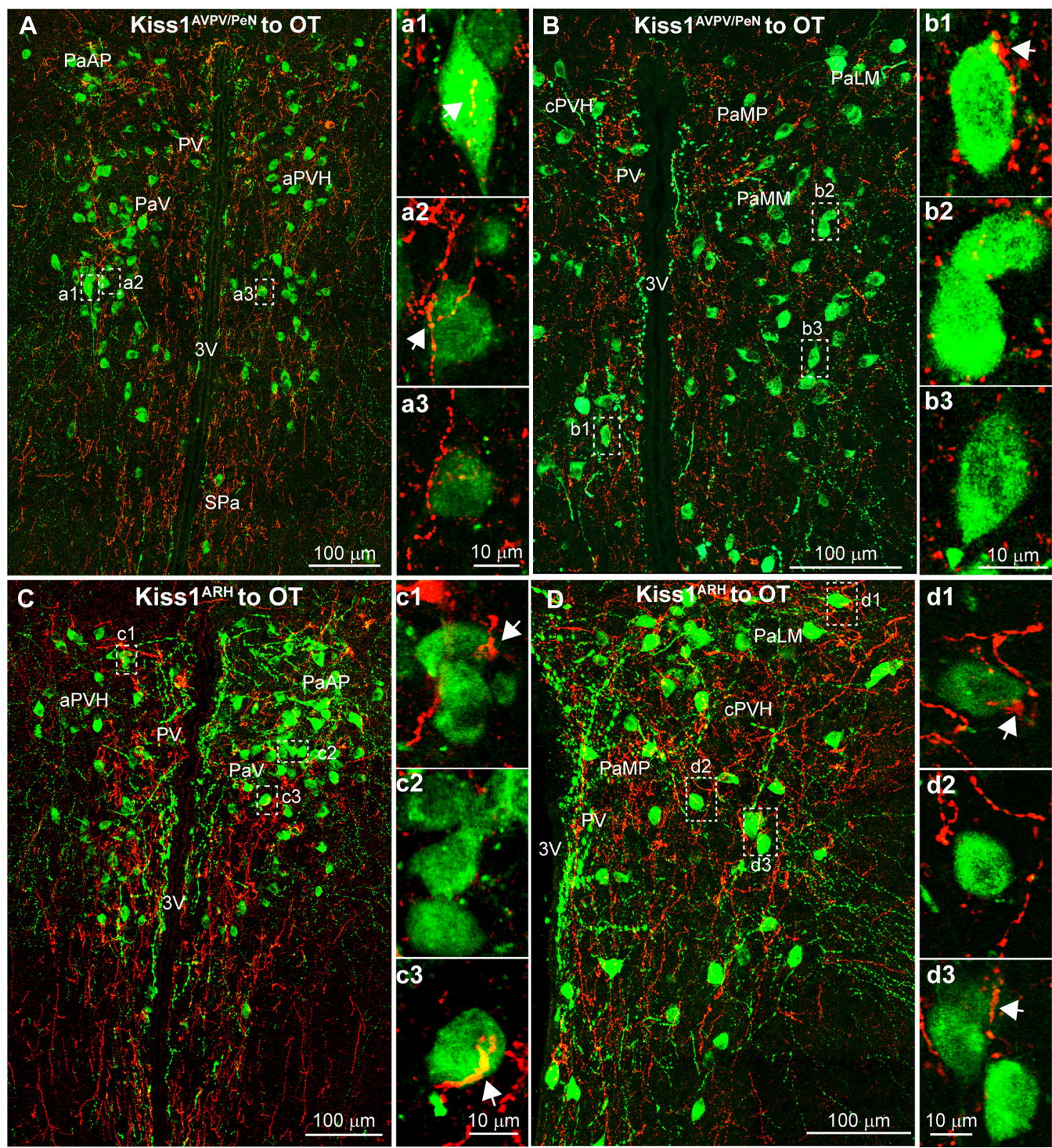

Figure 13. Kiss1 fiber projections to OT neurons in the PVH. Confocal image montage of Kiss 1 Cre.:ChR2-mCherry fibers in the PVH. Double label ICC was used to visualize mCherry (red) and OT neurons (green). $\boldsymbol{A}, \boldsymbol{C}$, In the aPVH, OT neurons are primarily located in the PaAP and the PaV regions with a smaller number present in the in the PV. a1-a3, Focused views of a single optical slice of individual neurons from $\boldsymbol{A}$. c1-c3, Focused views of a single optical slice of individual neurons from $\boldsymbol{C}$. $\boldsymbol{B}, \boldsymbol{D}$, In the cPVH, OT neurons are diffusely distributed through most the PVH. b1-b3, Focused views of single optical slice $\boldsymbol{B}$. d1-d3, Images from single optical slice in $\boldsymbol{D}$. See Table 2 for summary of the close contact analysis. For abbreviations, see Figures $3,7$.

capacitance of $14.1 \pm 1.0 \mathrm{pF}(n=10)$. Similar to the GABAergic Kiss $1^{\mathrm{AVPV} / \mathrm{PeN}}$ inputs to $\mathrm{PVH}$, the latency to response onset in $\mathrm{DMH}$ cells was $4.5 \pm 0.6 \mathrm{~ms}(n=13)$. This latency is consistent to that reported elsewhere when studying monosynaptic connections using optogenetics between two nuclei separated by a similar anatomic distance (Felix-Ortiz et al., 2013; Holloway et al., 2013). Again we used the rescue protocol to confirm a direct connection; that is, while TTX was effective at eliminating the light-evoked response, addition of the $\mathrm{K}^{+}$channel blockers 4-AP and TEA (Cousin and Robinson, 2000;
Petreanu et al., 2009) restored the response in the neuron (Fig. 16D), which was post hoc identified with scRT-PCR as expressing Cart mRNA (Fig. 16E).

\section{Kiss $1^{\mathrm{ARH}}$ neurons excite PVH and DMH neurons via glutamate release}

We also did whole-cell patch recordings using a standard internal solution from $\mathrm{PVH}$ and $\mathrm{DMH}$ neurons adjacent to Kiss1-ChR2:mCherry fibers in OVX Kiss $1^{\text {Cre:GFP }}$ mice that had received bilateral injections of AAV1-ChR2- 

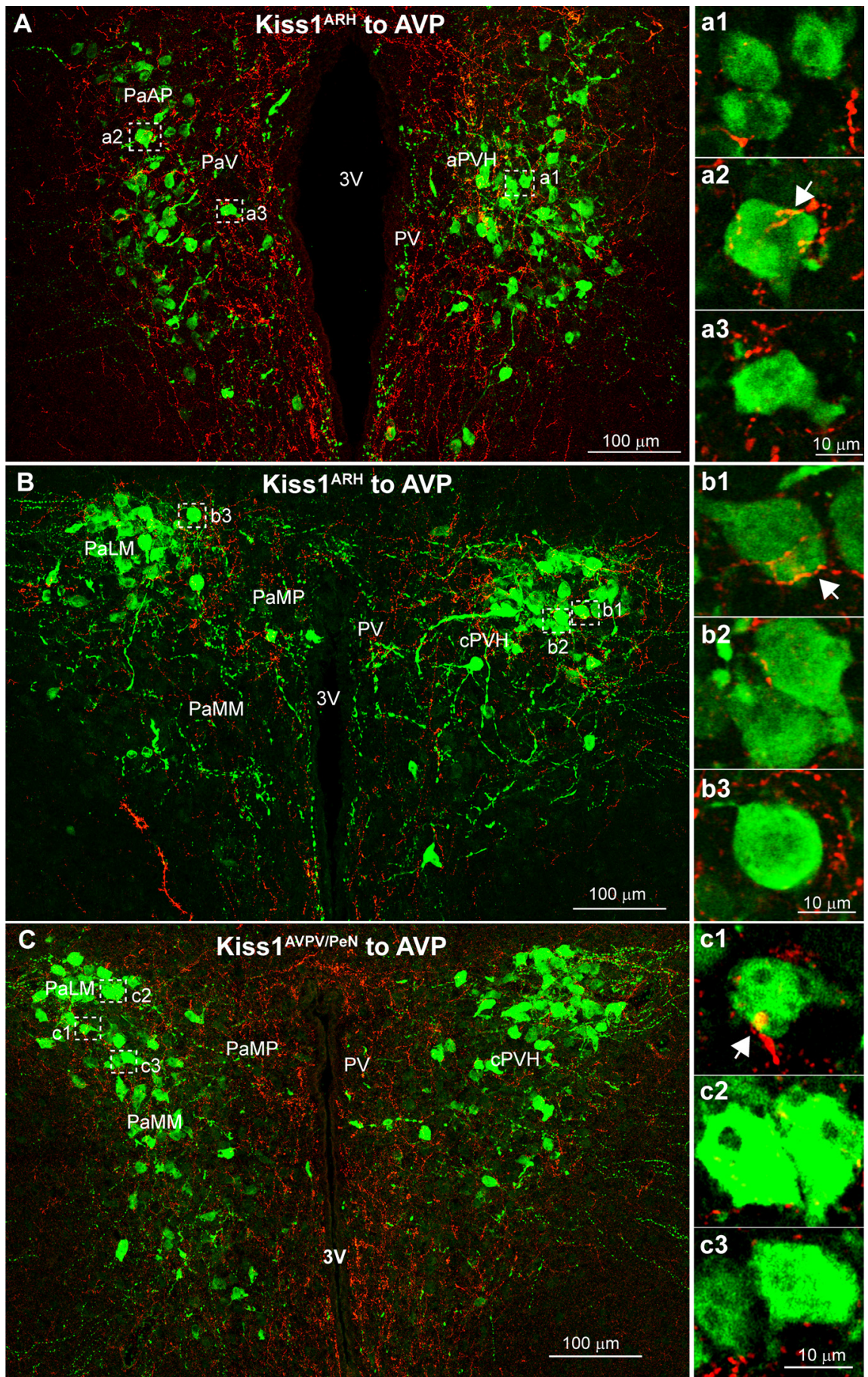

Figure 14. Kiss1 fiber projections to AVP neurons in the PVH. AVP neurons are also present in the aPVH but tend to be found more laterally with fewer cells near the $3 \mathrm{~V}$. A, AVP neurons are located in parvicellular regions of the aPVH such as the PaAP and PaV. a1-a3, Single optical plane images of Kiss $1^{A R H}:: C h R 2-m C h e r r y$ fibers that make close contact with AVP neurons. $\boldsymbol{B}$, In the more caudal PVH, AVP neurons are confined to tight clusters of cells in the PaLM. b1-b3, Single optical plane images reveal that Kiss $1^{\mathrm{ARH}}$ fibers make close contact with AVP neurons in the PaLM. C, Kiss $1^{\text {AVPV/PeN }}$ input onto AVP neurons were only investigated in the CPVH. A confocal image montage shows that many AVP neurons (green) are clustered in the lateral regions where Kiss $1^{\mathrm{AVPV} / \mathrm{PeN}}$ fibers make contact with AVP neurons in the PaLM and PaMM magnocellular regions. c1-c3, Single optical plane images focused on individual AVP cells from $\boldsymbol{C}$ demarcated by white boxes. See Table 2 for summary of the close contact analysis. 

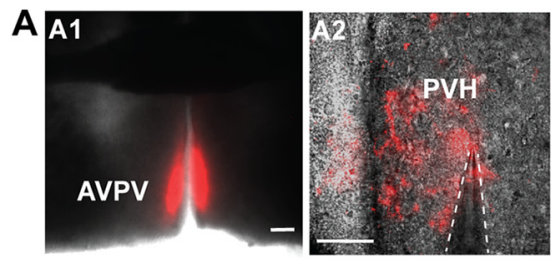

C

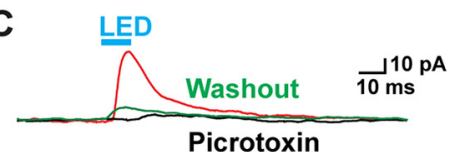

E<smiles>[CH+]=[FeH+]</smiles>

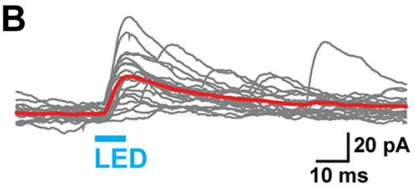

D
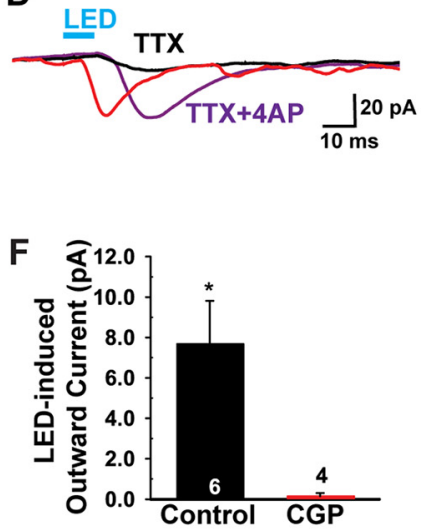

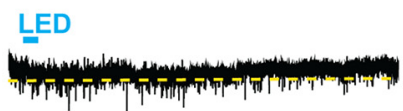

\section{Picrotoxin+CGP}

G

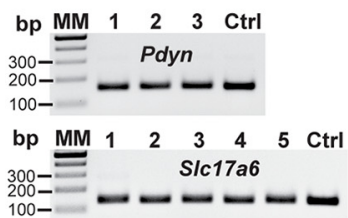

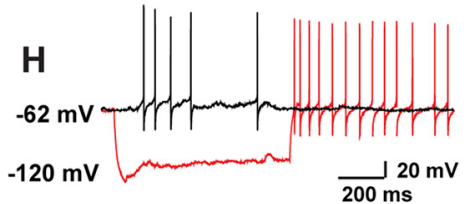

Figure 15. Postsynaptic responses to optogenetic stimulation of Kiss1 AVPV/PeN fibers release GABA onto PVH neurons. A1, Lowpower composite image of a coronal slice through AVPV. Injections of AAV-DIO:ChR2:mCherry into the AVPV/PeN labeled Kiss $1^{\text {AVPV/PeN }}$ neurons from rostral to caudal. A2, High-power composite image shows fluorescence projections are visible around the patched cells in the PVH. Low-power scale bar: $200 \mu \mathrm{m}$ (A1); high-power scale bar: $40 \mu \mathrm{m}$ (A2). B-C, Using a standard internal solution, whole-cell voltage clamp recordings were made in $\mathrm{PVH}$ neurons $\left(\mathrm{V}_{\text {hold }}=-10 \mathrm{mV}\right)$. $\boldsymbol{B}$, Fast outward currents were seen in response to blue light stimulation. Red trace is the averaged response. $\boldsymbol{C}$, The $\mathrm{GABA}_{\mathrm{A}}$ antagonist picrotoxin (100 $\left.\mu \mathrm{M}\right)$ effectively and reversibly blocked the optogenetically evoked outward currents to confirm GABAergic signaling. $\boldsymbol{D}$, The optogenetically evoked currents were also blocked by TTX $(1 \mu \mathrm{M})$, but recovered when the $\mathrm{K}^{+}$blockers 4 -AP $(0.5 \mathrm{~mm})$ and TEA (7.5 mM) were added to the bath when using high chloride internal solution (Vhold $=-60 \mathrm{mV}$ ). This "rescue" of the response is physiological evidence of a direct synaptic connection. $\boldsymbol{E}$, High-frequency optogenetic stimulation $(20 \mathrm{~Hz}, 10 \mathrm{~s})$ generated a slow IPSC in a PVH neuron using high chloride internal solution $\left(\mathrm{V}_{\text {hold }}=-60 \mathrm{mV}\right.$; upper trace). In another cell, after blocking the LED-induced $\mathrm{GABA}_{\mathrm{A}}$ responses with picrotoxin at $100 \mu \mathrm{m}$, high-frequency optogenetic stimulation $(20 \mathrm{~Hz}, 30 \mathrm{~s})$ using normal internal solution still generated a slow IPSC that recovered in $10 \mathrm{~min}$ (middle trace). Furthermore, the GABA ${ }_{B}$ antagonist CGP $55845(1 \mu \mathrm{m})$ blocked the slow IPSC response in the presence of picrotoxin in another cell (bottom trace). Blue bar below or above the recordings indicate LED stimulus (B-E). $\boldsymbol{F}$, Summary of the effects of CGP 55845 on the high-frequency optogenetic stimulation $(20 \mathrm{~Hz}, 10 \mathrm{~s})$-induced slow IPSC in PVH neurons (unpaired $t$ test, $t_{(8)}=2.826,{ }^{*} p=0.0223$ ). Data points represent the mean \pm SEM. Cell numbers are indicated. G, Representative gel images of scRT-PCR Pdyn and Vglut2 mRNA expression in eight responsive PVH neurons. MM, molecular markers; 1-3 and 1-5, the recorded PVH neurons; Ctrl, positive tissue control. $\boldsymbol{H}$, A representative trace of a Pdyn neuron showing a "sag" (h-current) with hyperpolarizing current injection and rebound burst firing in current clamp. Two of three Pdyn neurons exhibited an h-current.

mCherry into the ARH (Fig. 17A1-A3). Kiss $1^{\mathrm{ARH}}$ neurons are glutamatergic (Nestor et al., 2016; Qiu et al., 2016), and stimulation of Kiss ${ }^{\text {ARH }}$ fibers in the PVH excited PVH neurons (Fig. 17B). We recorded EPSCs (Fig. 17B) from $\mathrm{PVH}$ neurons with a mean latency of $5.1 \pm 0.4 \mathrm{~ms}(n=23)$, which was antagonized by the glutamate ionotropic blockers CNQX (AMPA) and AP5 (NMDA; data not shown). Moreover, TTX abrogated the photostimulated postsynaptic inward current (Fig. 17C), but the inward current was rescued with the addition of the $\mathrm{K}^{+}$channel blockers 4-AP and TEA to the bath (Cousin and Robinson, 2000; Petreanu et al., 2009), which is evidence for direct synaptic contact between Kiss $1^{\mathrm{ARH}}$ neurons and the postsynaptic responsive PVH neurons. These responsive neurons were located in the dorsomedial PVH with a resting membrane potential of $-62.7 \pm 3.5 \mathrm{mV}$, an input resistance of $1.1 \pm 0.1 \mathrm{G} \Omega$ and a capacitance of $19.1 \pm 0.9 \mathrm{pF}$ $(n=21$; Fig. 17A1). Ten of the neurons expressed Vglut2 

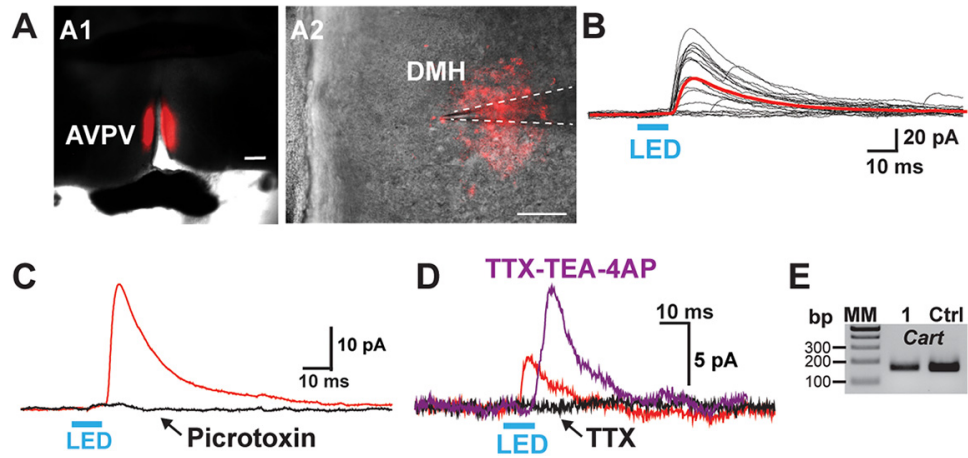

Figure 16. Postsynaptic responses to optogenetic stimulation of Kiss1 AVPV/PeN fibers release GABA onto DMH neurons. A1, Lowpower composite image of a coronal slice through AVPV. Injections of AAV-DIO:ChR2:mCherry into the AVPV/PeN labeled Kiss $1^{\text {AVPV/PeN }}$ neurons from rostral to caudal. High-power composite image shows fluorescence projections are visible around the patched cells in the DMH (A2). Low-power scale bar: $200 \mu \mathrm{m}(\boldsymbol{A 1})$; high-power scale bar: $40 \mu \mathrm{m}$ (A2). B-D, Using a standard internal solution, whole-cell voltage clamp recordings were made in $\mathrm{DMH}$ neurons $\left(\mathrm{V}_{\text {hold }}=-10 \mathrm{mV}\right)$. $\boldsymbol{B}$, Fast outward currents were seen in response to blue light stimulation. Red trace is the averaged response. $\boldsymbol{C}$, The outward currents were blocked by picrotoxin $(100 \mu \mathrm{M})$, demonstrating that currents were GABAergic. $\boldsymbol{D}$, Baseline postsynaptic responses (red) were blocked by TTX (black), but rescued after $\mathrm{K}^{+}$blockers $4-\mathrm{AP}$ and TEA (magenta) were added to the bath, indicating a direct synaptic connection between the Kiss $1^{\mathrm{AVPV} / \mathrm{PeN}}$ and DMH neurons. Blue bar below the recordings indicates LED stimulus (B-D). $\boldsymbol{E}$, Gel image of Cart mRNA expression of the "rescued" DMH neuron in $\boldsymbol{D}$. MM, molecular markers; 1, the recorded DMH cell; Ctrl, positive tissue control.

mRNA based on scRT-PCR identification, and five cells were found to express Pdyn mRNA, two of which also expressed Vglut2 (Fig. 17D). Again, the majority (80\%) of the responsive PVH neurons expressed an h-current, including four out of five Pdyn neurons exhibited a "sag" and rebound burst firing following a hyperpolarizing stimulus indicative of $h$ and T-currents, respectively (Fig. 17E).

Parvocellular DMH neurons with an input resistance of $0.9 \pm 0.2 \mathrm{G} \Omega$, a capacitance of $15.8 \pm 1.4 \mathrm{pF}$, and a RMP of $-59.3 \pm 4.0 \mathrm{mV}(n=10$; Fig. $17 \mathrm{A3})$ also exhibited fast glutamatergic synaptic input from Kiss $1^{\mathrm{ARH}}$ neurons; the inward current was blocked by the glutamate ionotropic receptor blockers AP5 (NMDA) and CNQX (AMPA; Fig. 17F). Once again, the latency to response onset was brief $(5.8 \pm 0.4, n=10)$, suggesting a direct connection. EPSCs were also frequently seen in slices taken from castrated males where the cells displayed an average resting membrane potential of $-56.6 \pm 2.4 \mathrm{mV}$, input resistance of $1.1 \pm 0.2 \mathrm{G} \Omega$ and a cell capacitance of $16.6 \pm 1.2 \mathrm{pF}$ $(n=12)$. The latency to response onset in all cells was $5.0 \pm 0.4 \mathrm{~ms}(n=22)$ similar to previous reports using optogenetics (Felix-Ortiz et al., 2013; Holloway et al., 2013). Furthermore, TTX abrogated the photostimulated postsynaptic inward current, but the current was rescued with the addition of the $\mathrm{K}^{+}$channel blockers 4-AP and TEA (Cousin and Robinson, 2000; Petreanu et al., 2009), again providing biophysical evidence for direct synaptic contact between Kiss $1^{\text {ARH }}$ neurons and parvocellular DMH neurons (Fig. 17G). Lastly, we harvested the optogenetically-stimulated neurons for sCRT-PCR identification, and four cells expressed Cart mRNA with one of these neurons also expressing the long form leptin receptor (Lepr; Fig. 17H).

\section{Discussion}

Although Kiss $1^{\mathrm{ARH}}$ and Kiss $1^{\mathrm{AVPV} / \mathrm{PeN}}$ neurons both send extensive projections to the ventro-lateral septum, BST and the PVH, they have distinct projection patterns to a number of hypothalamic areas including the VMPO, MnPO, MPA, DMH, and the ME. Functionally, we have found that activation of ChR2 expression in $\mathrm{PVH}$ or $\mathrm{DMH}$ nerve terminals from Kiss $1^{\mathrm{ARH}}$ neurons causes glutamate release and excitation of $\mathrm{PVH}$ and $\mathrm{DMH}$ neurons. In contrast, activation of ChR2 expression in nerve terminals from Kiss 1 AVPV/ $\mathrm{PeN}$ neurons causes hyperpolarization and inhibition of $\mathrm{PVH}$ and DMH neurons via GABA release. Therefore these different populations of Kiss1 neurons, in addition to their role to regulate reproduction, have the ability to differentially regulate nuclei, such as the PVH and $\mathrm{DMH}$, that are important for neuroendocrine and autonomic regulation of numerous functions (Fig. 18; Lee et al., 2013a,b; Piñol et al., 2014; Shah et al., 2014).

\section{Kiss1 neuronal input to GnRH neurons}

Currently we have shown in our Kiss $1^{\mathrm{Cre}}$ animal model, that Kiss $1^{\mathrm{AVPV} / \mathrm{PeN}}$ neurons send projections toward $\mathrm{GnRH}$ neuronal somas and form close contact with the majority of these neurons, confirming previous data (Yip et al., 2015). This was expected, in large part because of previous findings that Kiss $1^{\text {AVPV/PeN }}$ neurons directly activate $\mathrm{GnRH}$ neurons and appear to be responsible for the $\mathrm{GnRH}$ and $\mathrm{LH}$ surge at least in rodents (Clarkson et al., 2008; Qiu et al., 2016). Although, we did observe occasional close contacts between Kiss $1{ }^{\mathrm{ARH}}$ fibers and $\mathrm{GnRH}$ cells and proximal dendrites in the POA, Kiss $1{ }^{\mathrm{ARH}}$ neurons appear to primarily interact with $\mathrm{GnRH}$ nerve fibers and terminals in the ME area to regulate $\mathrm{GnRH}$ and subsequent $\mathrm{LH}$ pulsatility necessary for reproduction (Fox and Smith, 1985; O'Byrne et al., 1991; Mayer et al., 2010; Yip et al., 2015; Czieselsky et al., 2016; Qiu et al., 2016; Clarkson et al., 2017; Rønnekleiv et al., 2019; Voliotis et al., 2019; Liu et al., 2021). 


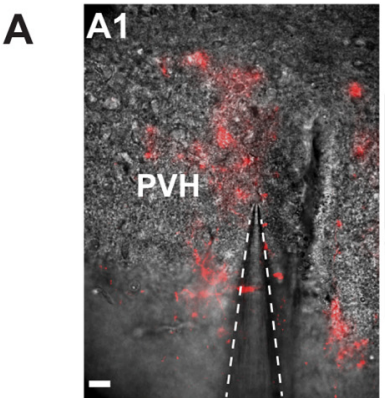

B $\mathrm{PVH}$
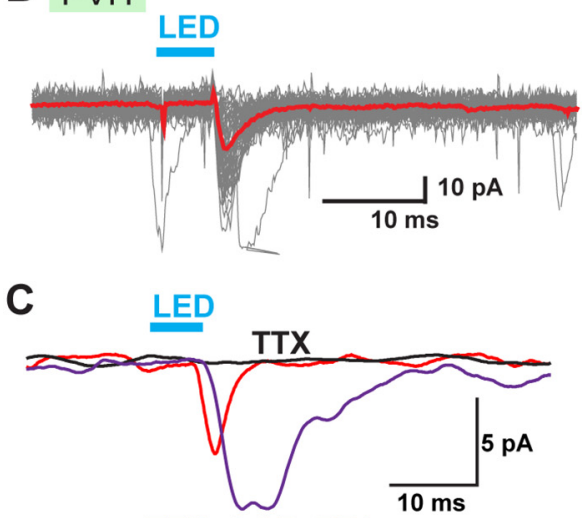

TTX+4-AP+TEA
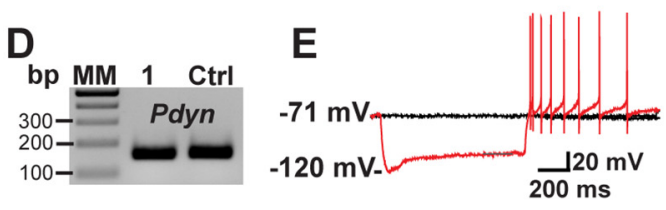

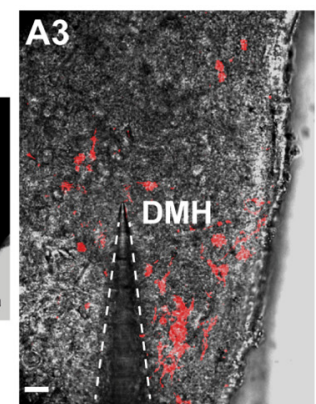

$\mathbf{F} \mathrm{DMH}$
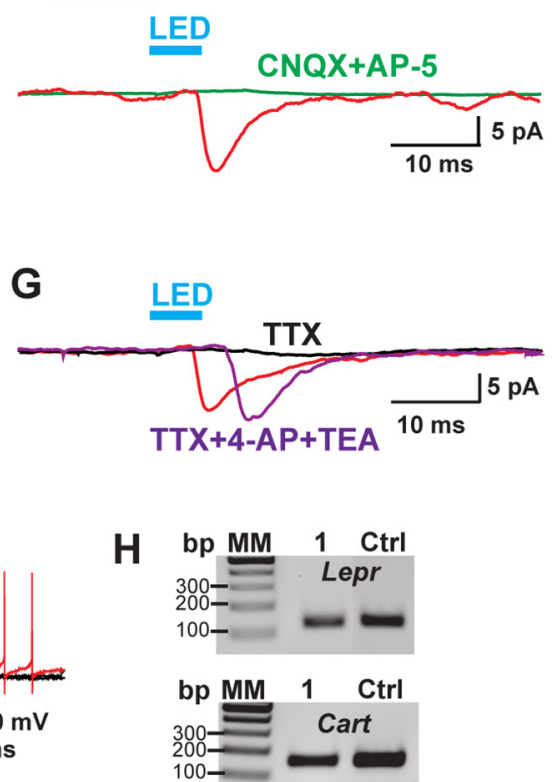

Figure 17. Photostimulation induced glutamate release from Kiss $1^{\mathrm{ARH}}$ fibers onto $\mathrm{PVH}$ and $\mathrm{DMH}$ neurons. A1, A3, High-power, overlay of DIC and epifluorescence (mCherry) images showing the Kiss 1 terminals expressing mCherry (red) around a patched cell in PVH $(\boldsymbol{A} 1)$ and DMH (A3). A2, Low-power image of a coronal section through the ARH from Kiss $1^{\text {Cre }}$ mouse that received dual injections of AAV-DIO-ChR2:mCherry. Scale bars: $40 \mu \mathrm{m}(\boldsymbol{A 1}, \boldsymbol{A 3})$ and $200 \mu \mathrm{m}(\boldsymbol{A 2})$. $\boldsymbol{B}-\boldsymbol{E}$, Blind patch recording in PVH neurons. $\boldsymbol{B}$, Fast glutamatergic current in voltage clamp $V_{\text {hold }}=-60 \mathrm{mV}$ following $5 \mathrm{~ms}$ of optostimulation. Red trace shows averaged response. Blue bar above recordings indicates LED stimulus. $\boldsymbol{C}$, The optogenetically evoked currents were blocked by TTX (1 $\mu \mathrm{M}$, black trace), but recovered when the $\mathrm{K}^{+}$blockers $4-\mathrm{AP}(0.5 \mathrm{~mm})$ and TEA $(7.5 \mathrm{~mm})$ were added to the bath (magenta trace). $\boldsymbol{D}$, A gel image of scRT-PCR of Pdyn expression in a recorded PVH neuron, which was documented in five responsive cells. MM, molecular markers; 1, the recorded PVH neuron; Ctrl, positive tissue control. E, 75\% of the Pdyn neurons exhibited a "sag" (h-current) with hyperpolarizing current injection and rebound burst firing in current clamp. $\boldsymbol{F}-\boldsymbol{H}$, Blind patch recording in DMH neurons. Photostimulation before (red trace) and after blockade (green trace) following CNQX (10 $\mu \mathrm{M})$ and AP5 (50 $\mu \mathrm{M})$ application. G, Photostimulation induced a fast EPSC following blue light stimulation (red trace). The response was abrogated in the presence of TTX (1 $\mu \mathrm{M}$, black trace) but rescued with the addition of the $\mathrm{K}^{+}$channel blockers 4-AP $(0.5 \mathrm{~mm})$ and TEA $(7.5 \mathrm{~mm}$; magenta trace). $\boldsymbol{H}$, Gel images of scRT-PCR of long form leptin receptor (Lepr) and Cart mRNA in the "rescued" DMH neuron in G. MM, molecular markers; 1 , the recorded DMH cell; Ctrl, positive tissue control.

\section{Kiss1 neurons and the SCN}

Currently, we found little or no evidence for direct Kiss1 input to the central core part of the SCN in agreement with previous studies (Clarkson et al., 2009; Padilla et al., 2019). However, AVP neurons at the dorsal shell region of the SCN, and AVP efferent projections toward the SPa zone appeared to be contacted by both Kiss $1^{\mathrm{AVPV} / \mathrm{Pen}}$ and Kiss $1^{A R H}$ fiber-projections, which would indicate that Kiss1 neurons may modulate directly or indirectly a subgroup of AVP-positive SCN neurons and their output in the SPa zone. In support of such interactions, it was recently found that permanently silencing Kiss $1^{\mathrm{ARH}}$ neurons (with tetanus toxin) caused animals to become obese because of a diurnal shift in eating pattern, although their overall food consumption was not increased (Padilla et al., 2019). Kiss $1^{\mathrm{ARH}}$-silenced mice in comparison to controls ate significantly less during the dark phase with increased food intake during the light phase, which after four to eight weeks led to obesity. Kiss $1^{\mathrm{ARH}}$ silenced mice were also less active during the dark phase. Therefore, circadian disruption in feeding and reduced activity in the dark appeared to be contributing factors to increased obesity in Kiss $1^{\mathrm{ARH}}$ silenced mice. In this respect, earlier studies showing that mice fed a high-fat diet during the 


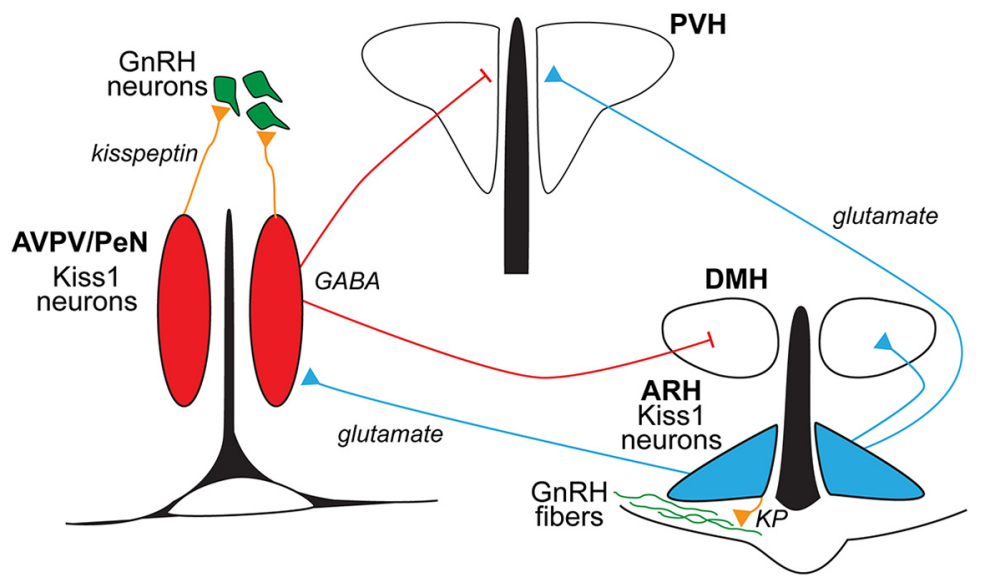

Figure 18. A highly schematic circuit diagram of anatomic and electrophysiological findings. The two populations of kisspeptin neurons (Kiss1 ${ }^{\text {AVPV/Pen }}$ and Kiss1 ${ }^{\mathrm{ARH}}$ ) show overlapping but distinct projections to multiple hypothalamic nuclei including: DB, POA, $\mathrm{SON}, \mathrm{PVH}$, and DMH. More importantly, the two populations can use in addition to peptides their unique amino acid neurotransmitters, GABA for Kiss $1^{\mathrm{AVPV} / \mathrm{Pen}}$ and glutamate for Kiss $1^{\mathrm{ARH}}$ neurons, to inhibit or excite parvocellular neurons in the PVH and DMH, areas that are known to control food intake and energy expenditure, respectively. These findings could be a general phenomenon for these two different populations of kisspeptin neurons. DB, diagonal band; POA, preoptic area; SON, supraoptic nucleus; PVH, paraventricular nucleus of the hypothalamus; $\mathrm{DMH}$, dorsomedial hypothalamus.

12-h light phase gain more weight than mice fed this diet during the 12-h dark phase also point to the importance of feeding pattern on body weight (Arble et al., 2009). It has also been shown previously that rats subjected to hypocaloric, early morning restricted feeding for several months exhibited decreased number of immunoreactive AVP neurons and decreased AVP mRNA levels without major anatomic changes overall in the SCN, an indication that SCN AVP neurons may be involved in regulating diurnal feeding patterns (Andrade et al., 2004).

Kiss $1^{\mathrm{ARH}}$ neurons co-express kisspeptin, NKB, Dynorphin and glutamate (Goodman et al., 2007; Cravo et al., 2011; Nestor et al., 2016). Silencing of Kiss $1^{\mathrm{ARH}}$ neurons would eliminate release of all of these neuropeptides/neurotransmitters. Therefore, it is unclear by what cellular mechanisms Kiss $1^{\mathrm{ARH}}$ neurons influence the SCN clock to coordinate feeding pattern and activity with the dark phase. On the other hand, deletion of vGlut2 in Kiss $1^{\mathrm{ARH}}$ neurons eliminates glutamate release and leads to conditioned place preference for sucrose, but does not increase body weight on normal mouse chow (Qiu et al., 2018). Collectively, these findings suggest that Kiss $1^{\mathrm{ARH}}$ neurons are involved in regulating energy homeostasis, in part via glutamate release onto NPY/AgRP and POMC neurons and in part via Kiss $1^{A R H}$ interaction with AVP neurons in the SCN to maintain diurnal feeding patterns (Qiu et al., 2018; Padilla et al., 2019).

\section{Kiss1 neurons and temperature regulation}

The hypothalamus is a key region of the brain involved in the control of core body temperature (Tc) and energy homeostasis, in part via E2 regulation (Qiu et al., 2006; Roepke et al., 2010). Neurons within the ARH, including NPY/AgRP, POMC, and Kiss1 (KNDy) neurons, are essential for the estrogenic control of energy homeostasis, and Kiss $1^{\mathrm{ARH}}$ neurons may also be involved in temperature regulation (Rance et al., 2013; Padilla et al., 2018; Rønnekleiv et al., 2019). Within the POA, the VMPO expresses warm-sensitive neurons that respond within seconds to increased ambient temperature, and glutamatergic and GABAergic neurons within the MnPO are sensitive to either heat or cold exposure (Tan et al., 2016; Abbott and Saper, 2017; Morrison and Nakamura, 2019). Importantly, these POA neurons are part of neurocircuitries that help to maintain a relatively constant Tc. It is well known that postmenopausal women lacking E2 may experience hot flushes, a periodic sensation of intense heat that negatively affects their quality of life (Freedman et al., 1995; Freedman, 2014). Kiss $1^{\mathrm{ARH}}$ neurons are proposed to play a key role in causing hot flushes based on observations that these neurons projects to preoptic thermoregulatory areas that express NK3R, in particular the $\mathrm{MnPO}$, and that ablation of Kiss $1^{\mathrm{ARH}}$ neurons partially blocks the effects of estrogens on thermoregulation (Krajewski et al., 2010). However, recently it was discovered that NK3R-expressing neurons in the MnPO are not activated by warm sensors in the skin and are not warm-sensitive neurons, although they play a role in reducing Tc (Krajewski-Hall et al., 2019). The authors concluded that KNDy neurons modulate thermosensory pathways indirectly for heat defense. Currently, we have shown that Kiss $1^{\mathrm{ARH}}$ neurons send extensive projections to the AVPV, MPO, and PeN nuclei, but have a very limited input to the temperature-sensitive neurons in the VMPO and MnPO. In contrast, Kiss $1^{\mathrm{AVPV} / \mathrm{PeN}}$ neurons project extensively throughout the $\mathrm{POA}$, including the VMPO and the MnPO regions. Therefore, our results support the idea of an indirect input from Kiss $1^{\mathrm{ARH}}$ neurons to POA warm-sensitive neurons, perhaps via activation of Kiss $1^{A V P V / P e N}$ neurons (Qiu et al., 2016, 2018). Clearly, additional studies are needed to elucidate how each of the Kiss1 neuronal groups may be involved in modulating temperature-regulating circuitries. 


\section{Kiss1 neurons and the PVH and SON}

Interestingly, we have demonstrated that the PVH appears to receive about equal fiber-input from Kiss $1^{\mathrm{AVPV} / \mathrm{PeN}}$ and Kiss ${ }^{\mathrm{ARH}}$ neurons. Using immunocytochemical staining for kisspeptin, several authors have documented that kisspeptin-positive fibers are located in the PVH; these studies, however, did not differentiate the origin of these fibers (Clarkson et al., 2009; Marraudino et al., 2017). The PVH is a complex, heterogeneous nucleus consisting of magnocellular and parvocellular neurons (Hallbeck et al., 2001; Stern, 2015). The neuroendocrine AVP and OT magnocellular neurons in the PVH and SON send projections to the posterior pituitary where AVP and OT are released into the circulation to regulate blood osmolality and milk ejection, respectively (Stern, 2015; Brown et al., 2020; Tasker et al., 2020). Currently, we have shown that neurons expressing either AVP or OT are among the PVH neurons receiving close-contact fiber-input from both Kiss $1^{\mathrm{AVPV} / \mathrm{PeN}}$ and Kiss $1^{\mathrm{ARH}}$ neurons. However, we found that OT neurons mainly in the SON are contacted directly by Kiss $1^{\mathrm{AVPV} / \mathrm{PeN}}$ neuronal fibers with few if any fibers contacting directly AVP-expressing SON neurons, and there is no apparent input to the SON from Kiss $1{ }^{\mathrm{ARH}}$ neurons. These data are consistent with findings in the rat that Kiss $1^{\mathrm{AVPV} / \mathrm{PeN}}$ neurons send extensive projections to the SON and SON perinuclear zone at the end of gestation to increase the activity of OT neurons at the time of parturition (Seymour et al., 2017).

The parvocellular $\mathrm{PVH}$ comprises different neuronal types, including neuroendocrine neurons (e.g., AVP) that project to the ME and regulate adrenocorticotropin hormone (ACTH) secretion from anterior pituitary corticotrophs (Verbalis et al., 1986). The parvocellular PVH also consists of preautonomic neurons (e.g., dynorphin, vGluT2, and OT) that send projections to brainstem and spinal cord areas and are important for autonomic functions (Hallbeck et al., 2001; Stern, 2001, 2015; Stocker et al., 2006; Rood and De Vries, 2011). Currently we have identified AVP-expressing and OT-expressing neurons within the different subregions of the PVH that receive Kiss1 fiber input as revealed by close contact (confocal) analysis of fibers originating from either or both $\mathrm{Kiss} 1^{\mathrm{AVPV} / \mathrm{PeN}}$ and Kiss $1^{\mathrm{ARH}}$ neurons. While useful in circuit mapping, close contact analysis does not provide conclusive evidence of synaptic contact. Therefore, we followed up these experiments with CRACM using optogenetic stimulation of Kiss $1^{\mathrm{ARH}}$ and Kiss $1^{\mathrm{AVPV} / \mathrm{PeN}}$ nerve-terminals to document that Pdyn-expressing and Vglut2-expressing $\mathrm{PVH}$ neurons in the medial parvocellular $\mathrm{PVH}$ receive direct excitatory input only from Kiss $1^{\mathrm{ARH}}$ neurons and direct inhibitory input only from Kiss $1^{\mathrm{AVPV} / \mathrm{PeN}}$ neurons. Indeed, we have found that low frequency stimulation of fiber-input from Kiss $1^{\mathrm{AVPV} / \mathrm{PeN}}$ neurons to $\mathrm{PVH}$ neurons caused inhibition via GABA release. Importantly, highfrequency stimulation also inhibited $\mathrm{PVH}$ neurons via the Gi,o-coupled GABA-B receptor blocked by CGP55845 rather than excitation via kisspeptin, which would also be released with high-frequency stimulation (Qiu et al.,
2016). Also, it has been shown previously that PVH neurons do not express the Kiss1 receptor (GPR54; Herbison et al., 2010), findings supported by our current data. These parvocellular PVH neurons are known to be critically involved in appetite regulation (Chang et al., 2007; Garfield et al., 2015; Li et al., 2018); however, the specific circuitries have not been completely documented and need to be further investigated. Interestingly, PVH dynorphin-expressing and enkephalin-expressing neurons exhibit increased mRNA expression and peptides in response to increased dietary fat consumption, which is known to promote additional feeding, a phenomenon called "fat-induced hyperphagia" (Chang et al., 2007). Also, there is glutamatergic input from the ARH onto Mc4r-expressing PVH neurons, which has been found to regulate satiety (Fenselau et al., 2017). The glutamatergic ARH to $\mathrm{PVH}$ projection was thought not to be from Kiss $1^{\mathrm{ARH}}$-expressing neurons based on the low response-rate following activation of $\mathrm{Kiss} 1^{\mathrm{ARH}}$ projections. In addition, stimulation of Kiss $1^{\mathrm{ARH}}$ neurons did not rapidly suppress feeding during the dark cycle (Fenselau et al., 2017). Therefore, although Kiss1 neurons have direct projections to and may regulate a number of neurons involved in feeding behavior including those expressing NPY/AgRP and POMC in the ARH and now dynorphin and vGluT2 in the PVH (current findings and Chang et al., 2007; Qiu et al., 2018), additional experiments are needed to more fully explore the role of the two populations of Kiss 1 neurons in controlling energy metabolism.

\section{Kiss1 neurons and the DMH}

Kisspeptin neurons and Kisspeptin fiber-input have been described in the DMH in a number of species including mouse, guinea pig, sheep, monkey and human (Franceschini et al., 2006; Clarkson et al., 2009; Hrabovszky et al., 2010; Lehman et al., 2010; Bosch et al., 2012). However, the origin and specific role of Kiss1 neuronal input to the DMH has not been investigated. The DMH neurons express cholecystokinin (CCK), NPY, CART, and LepR and have been implicated in temperature regulation, body weight regulation and brown adipose tissue (BAT) thermogenesis (Elias et al., 2000; Chen et al., 2004; Draper et al., 2010; Zhang et al., 2011; Tan et al., 2016; Morrison and Nakamura, 2019). Importantly, optogenetic stimulation in vivo of LepR neurons in the $\mathrm{DMH}$, some of which also co-express CART or NPY, induces energy expenditure through action on sympathetic and BAT circuitries (Elias et al., 2001; Zhang et al., 2011; Lee et al., 2013b). Moreover, ablation of LepR from DMH neurons causes weight gain by reducing energy expenditure and locomotor activity (Rezai-Zadeh et al., 2014). Currently we have documented that Kiss $1^{\mathrm{ARH}}$ neurons project to $\mathrm{DMH}$ neurons and optogenetic activation of their fiber-terminals excites $\mathrm{DMH}$ neurons, including those expressing LepR and CART, via glutamate release. Therefore, the Kiss $1^{\mathrm{ARH}}$ neurons might be involved in regulating energy expenditure via direct actions on the $\mathrm{DMH}$. In addition, temperature-sensitive POA neurons act directly on $\mathrm{DMH}$ neurons to regulate BAT activity. The inhibitory GABAergic output from the POA to $\mathrm{DMH}$ neurons leads to suppression of BAT thermogenesis during warm ambient conditions (Madden and Morrison, 2019). 
Currently we have found that Kiss $1^{\mathrm{AVPV} / \mathrm{PeN}}$ neurons send extensive fiber-projections to the $\mathrm{DMH}$, and optogenetic activation of these fibers induced an outward current via GABA release that inhibited DMH neurons. Therefore, Kiss $1^{\mathrm{AVPV} / \mathrm{PeN}}$ neurons may be involved in suppressing BAT thermogenesis via action on $\mathrm{DMH}$ neurons during heat exposure and, thus, have a role in regulating energy expenditure as well as core body temperature. Interestingly some $\mathrm{DMH}$ cells displayed two sets of responses with distinct latencies, and a subset of recordings taken in Kiss1::Ai32 mice showed mixed GABA/Glutamate inputs (two out of eighteen responsive neurons). Therefore, Kiss $1^{\mathrm{AVPV}}$ and $\mathrm{Kiss} 1^{\mathrm{ARH}}$ neurons appear capable of projecting to the same neurons. While glutamatergic inputs with two different latencies might reflect direct and indirect inputs, dual GABAergic responses must be via two mono-synaptic inputs. Also, although many postsynaptic responses were seen in the $\mathrm{DMH}$, the frequency of response was about half of what was recorded in the PVH. Therefore, further work needs to be done to characterize the $\mathrm{DMH}$ subpopulations targeted by Kiss1 fibers and focusing on specific DMH subpopulations may yield greater consistency in observing postsynaptic responses.

\section{Summary}

It is well documented that hypothalamic Kiss1 neurons are necessary for pubertal development and adult reproduction (De Roux et al., 2003; Seminara et al., 2003; d'Anglemont de Tassigny et al., 2007; Moore et al., 2019). In addition, these neurons send inhibitory and excitatory projections to multiple brain regions involved in functions such as metabolism, energy expenditure and temperature regulation. Although, Kiss $1{ }^{\mathrm{ARH}}$ neurons have been proposed to be involved in the regulation of core body temperature and may induce hot flash symptoms in mice (Padilla et al., 2018; Krajewski-Hall et al., 2019), Kiss $1^{\text {AVPV/PeN }}$ neurons appear to have the most extensive direct projections to temperature-sensitive areas (current findings). Moreover, we have documented direct projections of Kiss1 neurons to parvocellular neurons in the PVH and DMH (Fig. 18), which are known to be involved in regulating food intake and energy expenditure, respectively. Clearly, further studies are needed to elucidate the mechanisms by which Kiss1 neurons affect these other homeostatic functions.

\section{References}

Abbott SBG, Saper CB (2017) Median preoptic glutamatergic neurons promote thermoregulatory heat loss and water consumption in mice. J Physiol 595:6569-6583.

Andrade JP, Pereira PA, Silva SM, Sá SI, Lukoyanov NV (2004) Timed hypocaloric food restriction alters the synthesis and expression of vasopressin and vasoactive intestinal peptide in the suprachiasmatic nucleus. Brain Res 1022:226-233.

Arble DM, Bass J, Laposky AD, Vitaterna MH, Turek FW (2009) Circadian timing of food intake contributes to weight gain. Obesity (Silver Spring) 17:2100-2102.

Biag J, Huang Y, Gou L, Hintiryan H, Askarinam A, Hahn JD, Toga AW, Dong HW (2012) Cyto- and chemoarchitecture of the hypothalamic paraventricular nucleus in the C57BL/6J male mouse: a study of immunostaining and multiple fluorescent tract tracing. $J$ Comp Neurol 520:6-33.

Bosch MA, Xue C, Rønnekleiv OK (2012) Kisspeptin expression in guinea pig hypothalamus: effects of $17 \beta$-estradiol. J Comp Neurol 520:2143-2162.

Brown CH, Ludwig M, Tasker JG, Stern JE (2020) Somato-dendritic vasopressin and oxytocin secretion in endocrine and autonomic regulation. J Neuroendocrinol 32:e12856.

Chang GQ, Karatayev O, Ahsan R, Gaysinskaya V, Marwil Z, Leibowitz SF (2007) Dietary fat stimulates endogenous enkephalin and dynorphin in the paraventricular nucleus: role of circulating triglycerides. Am J Physiol Endocrinol Metab 292:E561-E570.

Chen P, Williams SM, Grove KL, Smith MS (2004) Melanocortin 4 receptor-mediated hyperphagia and activation of neuropeptide $Y$ expression in the dorsomedial hypothalamus during lactation. $J$ Neurosci 24:5091-5100.

Clarkson J, d'Anglemont de Tassigny X, Moreno AS, Colledge WH, Herbison AE (2008) Kisspeptin-GPR54 signaling is essential for preovulatory gonadotropin-releasing hormone neuron activation and the luteinizing hormone surge. J Neurosci 28:8691-8697.

Clarkson J, d'Anglemont de Tassigny X, Colledge WH, Caraty A, Herbison AE (2009) Distribution of kisspeptin neurones in the adult female mouse brain. J Neuroendocrinol 21:673-682.

Clarkson J, Han SY, Piet R, McLennan T, Kane GM, Ng J, Porteous RW, Kim JS, Colledge WH, Iremonger KJ, Herbison AE (2017) Definition of the hypothalamic $\mathrm{GnRH}$ pulse generator in mice. Proc Natl Acad Sci USA 114:E10216-E10223.

Cousin MA, Robinson PJ (2000) $\mathrm{Ca}(2+)$ influx inhibits dynamin and arrests synaptic vesicle endocytosis at the active zone. J Neurosci 20:949-957.

Cravo RM, Margatho LO, Osborne-Lawrence S, Donato JJ, Atkin S, Bookout AL, Rovinsky S, Frazão R, Lee CE, Gautron L, Zigman JM, Elias CF (2011) Characterization of Kiss1 neurons using transgenic mouse models. Neuroscience 173:37-56.

Czieselsky K, Prescott M, Porteous R, Campos P, Clarkson J, Steyn FJ, Campbell RE, Herbison AE (2016) Pulse and surge profiles of luteinizing hormone secretion in the mouse. Endocrinology 157:4794-4802.

d'Anglemont de Tassigny X, Fagg LA, Dixon JPC, Day K, Leitch HG, Hendrick AG, Zahn D, Franceschini I, Caraty A, Carlton MBL, Aparicio SAJR, Colledge WH (2007) Hypogonadotropic hypogonadism in mice lacking a functional KiSS 1 gene. Proc Natl Acad Sci USA 104:10714-10719.

Dave JR, Rubinstein N, Eskay RL (1985) Evidence that b-endorphin binds to specific receptors in rat peripheral tissues and stimulates the adenylate cyclase-adenosine 3',5'-monophosphate system. Endocrinology 117:1389-1396.

De Roux N, Genin E, Carel J-C, Matsuda F, Chaussain J-L, Milgrom E (2003) Hypogonadotropic hypogonadism due to loss of function of the KiSS 1-derived peptide receptor GPR54. Proc Natl Acad Sci USA 100:10972-10976.

Draper S, Kirigiti M, Glavas M, Grayson B, Chong CNA, Jiang B, Smith MS, Zeltser LM, Grove KL (2010) Differential gene expression between neuropeptide $Y$ expressing neurons of the dorsomedial nucleus of the hypothalamus and the arcuate nucleus: microarray analysis study. Brain Res 1350:139-150.

Elias CF, Kelly JF, Lee CE, Ahima RS, Drucker DJ, Saper CB, Elmquist JK (2000) Chemical characterization of leptin-activated neurons in the rat brain. $\mathrm{J}$ Comp Neurol 423:261-281.

Elias CF, Lee CE, Kelly JF, Ahima RS, Kuhar M, Saper CB, Elmquist JK (2001) Characterization of CART neurons in the rat and human hypothalamus. J Comp Neurol 432:1-19.

Ellinwood WE, Rønnekleiv OK, Kelly MJ, Resko JA (1985) A new antiserum with conformational specificity for LHRH: usefulness for radioimmunoassay and immunocytochemistry. Peptides 6:45-52.

Felix-Ortiz AC, Beyeler A, Seo C, Leppla Christopher A, Wildes CP, Tye KM (2013) BLA to VHPC inputs modulate anxiety-related behaviors. Neuron 79:658-664.

Fenselau H, Campbell JN, Verstegen AM, Madara JC, Xu J, Shah BP, Resch JM, Yang Z, Mandelblat-Cerf Y, Livneh Y, Lowell BB 
(2017) A rapidly acting glutamatergic $A R C \rightarrow P V H$ satiety circuit postsynaptically regulated by $\alpha-\mathrm{MSH}$. Nat Neurosci 20:42-51.

Fox SR, Smith MS (1985) Changes in the pulsatile pattern of luteinizing hormone secretion during the rat estrous cycle. Endocrinology 116:1485-1492.

Franceschini I, Lomet D, Cateau M, Delsol G, Tillet Y, Caraty A (2006) Kisspeptin immunoreactive cells of the ovine preoptic area and arcuate nucleus co-express estrogen receptor alpha. Neurosci Lett 401:225-230.

Freedman RR (2014) Menopausal hot flashes: mechanisms, endocrinology, treatment. J Steroid Biochem Mol Biol 142:115-120.

Freedman RR, Norton D, Woodward S, Cornélissen G (1995) Core body temperature and circadian rhythm of hot flashes in menopausal women. J Clin Endocrinol Metab 80:2354-2358.

Garfield AS, Li C, Madara JC, Shah BP, Webber E, Steger JS, Campbell JN, Gavrilova O, Lee CE, Olson DP, Elmquist JK, Tannous BA, Krashes MJ, Lowell BB (2015) A neural basis for melanocortin-4 receptor-regulated appetite. Nat Neurosci 18:863871.

Goodman RL, Lehman MN, Smith JT, Coolen LM, de Oliveira CVR, Jafarzadehshirazi MR, Pereira A, Iqbal J, Caraty A, Ciofi P, Clarke IJ (2007) Kisspeptin neurons in the arcuate nucleus of the ewe express both dynorphin $A$ and neurokinin B. Endocrinology 148:5752-5760.

Gottsch ML, Popa SM, Lawhorn JK, Qiu J, Tonsfeldt KJ, Bosch MA, Kelly MJ, Rønnekleiv OK, Sanz E, McKnight GS, Clifton DK, Palmiter RD, Steiner RA (2011) Molecular properties of Kiss1 neurons in the arcuate nucleus of the mouse. Endocrinology 152:4298-4309.

Grachev P, Porter KL, Coolen LM, McCosh RB, Connors JM, Hileman SM, Lehman MN, Goodman RL (2016) Surge-like luteinising hormone secretion induced by retrochiasmatic area NK3R activation is mediated primarily by arcuate kisspeptin neurones in the ewe. J Neuroendocrinol 28:6.

Hallbeck M, Larhammar D, Blomqvist A (2001) Neuropeptide expression in rat paraventricular hypothalamic neurons that project to the spinal cord. J Comp Neurol 433:222-238.

Herbison AE, d'Anglemont de Tassigny X, Doran J, Colledge WH (2010) Distribution and postnatal development of Gpr54 gene expression in mouse brain and gonadotropin-releasing hormone neurons. Endocrinology 151:312-321.

Holloway BB, Stornetta RL, Bochorishvili G, Erisir A, Viar KE, Guyenet PG (2013) Monosynaptic glutamatergic activation of locus cand Other lower brainstem noradrenergic neurons by the C1 cells in mice. J Neurosci 33:18792-18805.

Hrabovszky E (2014) Neuroanatomy of the human hypothalamic kisspeptin system. Neuroendocrinology 99:33-48.

Hrabovszky E, Ciofi P, Vida B, Horvath MC, Keller E, Caraty A, Bloom SR, Ghatei MA, Dhillo WS, Liposits Z, Kallo I (2010) The kisspeptin system of the human hypothalamus: sexual dimorphism and relationship with gonadotropin-releasing hormone and neurokinin B neurons. Eur J Neurosci 31:1984-1998.

King JC, Tobet SA, Snavely FL, Arimura AA (1982) LHRH immunopositive cells and their projections to the median eminence and organum vasculosum of the lamina terminalis. J Comp Neurol 209:287-300.

Krajewski SJ, Burke MC, Anderson MJ, McMullen NT, Rance NE (2010) Forebrain projections of arcuate neurokinin B neurons demonstrated by anterograde tract-tracking and monosodium glutamate lesions in the rat. Neuroscience 166:680-697.

Krajewski-Hall SJ, Miranda Dos Santos F, McMullen NT, Blackmore EM, Rance NE (2019) Glutamatergic neurokinin 3 receptor neurons in the median preoptic nucleus modulate heat-defense pathways in female mice. Endocrinology 160:803-816.

Lee SJ, Kirigiti M, Lindsley SR, Loche A, Madden CJ, Morrison SF, Smith MS, Grove KL (2013a) Efferent projections of neuropeptide Y-expressing neurons of the dorsomedial hypothalamus in chronic hyperphagic models. J Comp Neurol 521:1891-1914.

Lee SJ, Verma S, Simonds SE, Kirigiti MA, Kievit P, Lindsley SR, Loche A, Smith MS, Cowley MA, Grove KL (2013b) Leptin stimulates neuropeptide $Y$ and cocaine amphetamine-regulated transcript coexpressing neuronal activity in the dorsomedial hypothalamus in diet-induced obese mice. J Neurosci 33:1530615317.

Lehman MN, Merkley CM, Coolen LM, Goodman RL (2010) Anatomy of the kisspeptin neural network in mammals. Brain Res 1364:90102.

Lehman MN, Hileman SM, Goodman RL (2013) Neuroanatomy of the kisspeptin signaling system in mammals: comparative and developmental aspects. Adv Exp Med Biol 784:27-62.

Li Y, Zeng J, Zhang J, Yue C, Zhong W, Liu Z, Feng Q, Luo M (2018) Hypothalamic circuits for predation and evasion. Neuron 97:911924.e5.

Liu X, Yeo SH, McQuillan HJ, Herde MK, Hessler S, Cheong I, Porteous R, Herbison AE (2021) Highly redundant neuropeptide volume co-transmission underlying episodic activation of the $\mathrm{GnRH}$ neuron dendron. Elife 10:e62455.

Luther JA, Tasker JG (2000) Voltage-gated currents distinguish parvocellular from magnocellular neurones in the rat hypothalamic paraventricular nucleus. J Physiol 523:193-209.

Madden CJ, Morrison SF (2019) Central nervous system circuits that control body temperature. Neurosci Lett 696:225-232.

Marraudino M, Miceli D, Farinetti A, Ponti G, Panzica G, Gotti S (2017) Kisspeptin innervation of the hypothalamic paraventricular nucleus: sexual dimorphism and effect of estrous cycle in female mice. J Anat 230:775-786.

Mayer C, Acosta-Martinez M, Dubois SL, Wolfe A, Radovick S, Boehm U, Levine JE (2010) Timing and completion of puberty in female mice depend on estrogen receptor $\alpha$-signaling in kisspeptin neurons. Proc Natl Acad Sci USA 107:22693-22698.

Moore AM, Coolen LM, Lehman MN (2019) Kisspeptin/Neurokinin B/ Dynorphin (KNDy) cells as integrators of diverse internal and external cues: evidence from viral-based monosynaptic tract-tracing in mice. Sci Rep 9:14768.

Morris M, Stevens SW, Adams MR (1980) Plasma oxytocin during pregnancy and lactation in the cynomolgus monkey. Biol Reprod 23:782-787.

Morrison SF, Nakamura K (2019) Central mechanisms for thermoregulation. Annu Rev Physiol 81:285-308.

Navarro VM, Gottsch ML, Chavkin C, Okamura H, Clifton DK, Steiner RA (2009) Regulation of gonadotropin-releasing hormone secretion by kisspeptin/dynorphin/neurokinin B neurons in the arcuate nucleus of the mouse. J Neurosci 29:11859-11866.

Nestor CC, Qiu J, Padilla SL, Zhang C, Bosch MA, Fan W, Aicher SA, Palmiter RD, Rønnekleiv OK, Kelly MJ (2016) Optogenetic stimulation of arcuate nucleus Kiss1 neurons reveals a steroid-dependent glutamatergic input to POMC and AgRP neurons in male mice. Mol Endocrinol 30:630-644.

O'Byrne KT, Thalabard JC, Grosser PM, Wilson RC, Williams CL, Chen MD, Ladendorf D, Hotchkiss J, Knobil E (1991) Radiotelemetric monitoring of hypothalamic gonadotropin-releasing hormone pulse generator activity throughout the menstrual cycle of the rhesus monkey. Endocrinology 129:1207-1214.

Oakley AE, Clifton DK, Steiner RA (2009) Kisspeptin signaling in the brain. Endocr Rev 30:713-743.

Padilla SL, Johnson CW, Barker FD, Patterson MA, Palmiter RD (2018) A neural circuit underlying the generation of hot flushes. Cell Rep 24:271-277.

Padilla SL, Perez JG, Ben-Hamo M, Johnson CW, Sanchez REA, Bussi IL, Palmiter RD, de la Iglesia HO (2019) Kisspeptin neurons in the arcuate nucleus of the hypothalamus orchestrate circadian rhythms and metabolism. Curr Biol 29:592-604.e4.

Petreanu L, Mao T, Sternson SM, Svoboda K (2009) The subcellular organization of neocortical excitatory connections. Nature 457:1142-1145.

Piet R, Kalil B, McLennan T, Porteous R, Czieselsky K, Herbison AE (2018) Dominant neuropeptide cotransmission in kisspeptinGABA regulation of $\mathrm{GnRH}$ neuron firing driving ovulation. J Neurosci 38:6310-6322. 
Piñol RA, Jameson H, Popratiloff A, Lee NH, Mendelowitz D (2014) Visualization of oxytocin release that mediates paired pulse facilitation in hypothalamic pathways to brainstem autonomic neurons. PLoS One 9:e112138.

Qiu J, Bosch MA, Tobias SC, Krust A, Graham S, Murphy S, Korach KS, Chambon P, Scanlan TS, Rønnekleiv OK, Kelly MJ (2006) A Gprotein-coupled estrogen receptor is involved in hypothalamic control of energy homeostasis. J Neurosci 26:5649-5655.

Qiu J, Nestor CC, Zhang C, Padilla SL, Palmiter RD, Kelly MJ, Rønnekleiv OK (2016) High-frequency stimulation-induced peptide release synchronizes arcuate kisspeptin neurons and excites GnRH neurons. Elife 5:e16246.

Qiu J, Rivera HM, Bosch MA, Padilla SL, Stincic TL, Palmiter RD, Kelly MJ, Rønnekleiv OK (2018) Estrogenic-dependent glutamatergic neurotransmission from kisspeptin neurons governs feeding circuits in females. Elife 7:e35656.

Rance NE, Dacks PA, Mittelman-Smith MA, Romanovsky AA, Krajewski-Hall SJ (2013) Modulation of body temperature and LH secretion by hypothalamic KNDy (kisspeptin, neurokinin B and dynorphin) neurons: a novel hypothesis on the mechanism of hot flushes. Front Neuroendocrinol 34:211-227.

Rezai-Zadeh K, Yu S, Jiang Y, Laque A, Schwartzenburg C, Morrison CD, Derbenev AV, Zsombok A, Münzberg H (2014) Leptin receptor neurons in the dorsomedial hypothalamus are key regulators of energy expenditure and body weight, but not food intake. Mol Metab 3:681-693.

Roepke TA, Bosch MA, Rick EA, Lee B, Wagner EJ, Seidlova-Wuttke D, Wuttke W, Scanlan TS, Rønnekleiv OK, Kelly MJ (2010) Contribution of a membrane estrogen receptor to the estrogenic regulation of body temperature and energy homeostasis. Endocrinology 151:4926-4937.

Rønnekleiv OK, Kelly MJ (1986) Luteinizing hormone-releasing hormone neuronal system during the estrous cycle of the female rat: effects of surgically induced persistent estrus. Neuroendocrinology 43:564-576.

Rønnekleiv OK, Loose MD, Erickson KR, Kelly MJ (1990) A method for immunocytochemical identification of biocytin-labeled neurons following intracellular recording. Biotechniques 9:432-438.

Rønnekleiv OK, Qiu J, Kelly MJ (2019) Arcuate kisspeptin neurons coordinate reproductive activities with metabolism. Semin Reprod Med 37:131-140.

Rood BD, De Vries GJ (2011) Vasopressin innervation of the mouse (Mus musculus) brain and spinal cord. J Comp Neurol 519:2434-2474.

Schindelin J, Arganda-Carreras I, Frise E, Kaynig V, Longair M, Pietzsch T, Preibisch S, Rueden C, Saalfeld S, Schmid B, Tinevez JY, White DJ, Hartenstein V, Eliceiri K, Tomancak P, Cardona A (2012) Fiji: an open-source platform for biological-image analysis. Nat Methods 9:676-682.

Seminara SB, Messager S, Chatzidaki EE, Thresher RR, Acierno JS, Shagoury JK, Bo-Abbas Y, Kuohung W, Schwinof KM, Hendrick AG, Zahn D, Dixon J, Kaiser UB, Slaugenhaupt SA, Gusella JF, O'Rahilly S, Carlton MBL, Crowley WF, Aparicio SAJR, Colledge WH (2003) The GPR54 gene as a regulator of puberty. N Engl J Med 349:1614-1627.

Seymour AJ, Scott V, Augustine RA, Bouwer GT, Campbell RE, Brown CH (2017) Development of an excitatory kisspeptin projection to the oxytocin system in late pregnancy. J Physiol 595:825838.

Shah BP, Vong L, Olson DP, Koda S, Krashes MJ, Ye C, Yang Z, Fuller PM, Elmquist JK, Lowell BB (2014) MC4R-expressing glutamatergic neurons in the paraventricular hypothalamus regulate feeding and are synaptically connected to the parabrachial nucleus. Proc Natl Acad Sci USA 111:13193-13198.

Smith JT (2008) Kisspeptin signalling in the brain: steroid regulation in the rodent and ewe. Brain Res Rev 57:288-298.

Smith JT, Cunningham MJ, Rissman EF, Clifton DK, Steiner RA (2005) Regulation of Kiss1 gene expression in the brain of the female mouse. Endocrinology 146:3686-3692.
Stern JE (2001) Electrophysiological and morphological properties of pre-autonomic neurones in the rat hypothalamic paraventricular nucleus. J Physiol 537:161-177.

Stern JE (2015) Neuroendocrine-autonomic integration in the paraventricular nucleus: novel roles for dendritically released neuropeptides. J Neuroendocrinol 27:487-497.

Stocker SD, Simmons JR, Stornetta RL, Toney GM, Guyenet PG (2006) Water deprivation activates a glutamatergic projection from the hypothalamic paraventricular nucleus to the rostral ventrolateral medulla. J Comp Neurol 494:673-685.

Suter KJ, Song WJ, Sampson TL, Wuarin JP, Saunders JT, Dudek FE, Moenter SM (2000) Genetic targeting of green fluorescent protein to gonadotropin-releasing hormone neurons: characterization of whole-cell electrophysiological properties and morphology. Endocrinology 141:412-419.

Tan CL, Cooke EK, Leib DE, Lin Y-C, Daly GE, Zimmerman CA, Knight ZA (2016) Warm-sensitive neurons that control body temperature. Cell 167:47-59.

Tasker JG, Prager-Khoutorsky M, Teruyama R, Lemos JR, Amstrong WE (2020) Advances in the neurophysiology of magnocellular neuroendocrine cells. J Neuroendocrinol 32:e12826.

Tolson KP, Garcia C, Yen S, Simonds S, Stefanidis A, Lawrence A, Smith JT, Kauffman AS (2014) Impaired kisspeptin signaling decreases metabolism and promotes glucose intolerance and obesity. J Clin Invest 124:3075-3079.

Uenoyama Y, Inoue N, Pheng V, Homma T, Takase K, Yamada S, Ajiki K, Ichikawa M, Okamura H, Maeda K-I, Tsukamura H (2011) Ultrastructural evidence of kisspeptin-gonadotrophin-releasing hormone $(\mathrm{GnRH})$ interaction in the median eminence of female rats: implication of axo-axonal regulation of $\mathrm{GnRH}$ release. J Neuroendocrinol 23:863-870.

Verbalis JG, Baldwin EF, Rønnekleiv OK, Robinson AG (1986) In vitro release of vasopressin and oxytocin from rat median eminence tissue. Neuroendocrinology 42:481-488.

Viau V, Sawchenko PE (2002) Hypophysiotropic neurons of the paraventricular nucleus respond in spatially, temporally, and phenotypically differentiated manners to acute vs. repeated restraint stress: rapid publication. J Comp Neurol 445:293-307.

Voliotis M, Li XF, De Burgh R, Lass G, Lightman SL, O’Byrne KT, Tsaneva-Atanasova K (2019) The origin of $\mathrm{GnRH}$ pulse generation: an integrative mathematical-experimental approach. J Neurosci 39:9738-9747.

Xu Y, Wu Z, Sun H, Zhu Y, Kim Eun R, Lowell Bradford B, Arenkiel Benjamin R, Xu Y, Tong Q (2013) Glutamate mediates the function of melanocortin receptor 4 on Sim1 neurons in body weight regulation. Cell Metab 18:860-870.

Yeo SH, Kyle V, Morris PG, Jackman S, Sinnett-Smith LC, Schacker M, Chen C, Colledge WH (2016) Visualisation of kiss1 neurone distribution using a kiss1-CRE transgenic mouse. J Neuroendocrinol 28.

Yip SH, Boehm U, Herbison AE, Campbell RE (2015) Conditional viral tract tracing delineates the projections of the distinct kisspeptin neuron populations to gonadotropin-releasing hormone $(\mathrm{GnRH})$ neurons in the mouse. Endocrinology 156:2582-2594.

Zhang C, Tonsfeldt KJ, Qu J, Bosch MA, Kobayashi K, Steiner RA, Kelly MJ, Rønnekleiv OK (2013) Molecular mechanisms that drive estradiol-dependent burst firing of Kiss 1 neurons in the rostral periventricular preoptic area. Am J Physiol Endocrinol Metab 305: E1384-E1397.

Zhang C, Bosch MA, Qiu J, Rønnekleiv OK, Kelly MJ (2015) $17 \beta$-estradiol increases persistent $\mathrm{Na}^{+}$current and excitability of AVPV/ PeN Kiss1 neurons in female mice. Mol Endocrinol 29:518-527.

Zhang Y, Kerman IA, Laque A, Nguyen P, Faouzi M, Louis GW, Jones JC, Rhodes C, Münzberg H (2011) Leptin-receptor-expressing neurons in the dorsomedial hypothalamus and median preoptic area regulate sympathetic brown adipose tissue circuits. J Neurosci 31:1873-1884. 